NBER WORKING PAPER SERIES

\title{
GINIS IN GENERAL EQUILIBRIUM: \\ TRADE, TECHNOLOGY AND SOUTHERN INEQUALITY
}

\author{
Susan Chun Zhu \\ Daniel Trefler \\ Working Paper 8446 \\ http://www.nber.org/papers/w8446 \\ NATIONAL BUREAU OF ECONOMIC RESEARCH \\ 1050 Massachusetts Avenue \\ Cambridge, MA 02138 \\ August 2001
}

We are indebted to Nadia Soboleva and other members of the University of Toronto International Trade Workshop for many helpful comments. Generous funding was provided by Canada's Social Science and Humanities Research Council (SSHRC) grant number 72016040. The views expressed herein are those of the authors and not necessarily those of the National Bureau of Economic Research.

(C) 2001 by Susan Chun Zhu and Daniel Trefler. All rights reserved. Short sections of text, not to exceed two paragraphs, may be quoted without explicit permission provided that full credit, including $\subset$ notice, is given to the source. 
Ginis in General Equilibrium: Trade, Technology and Southern Inequality

Susan Chun Zhu and Daniel Trefler

NBER Working Paper No. 8446

August 2001

JEL No. F1

\begin{abstract}
$\underline{\text { ABSTRACT }}$
Within developing and newly industrialized countries, rising wage inequality is both common and highly correlated with export growth. This is incompatible with the Stolper-Samuelson theorem, but suggestive of a role for technological catch-up. We develop this insight using a model that features both Ricardian and endowments-based comparative advantage. In this model Southern catch-up induces a correlation between rising inequality and export growth. It also induces a shift in trade patterns that results in skill upgrading and rising inequality in both the South and the North. A rudimentary empirical exercise reveals that, as predicted, Southern skill upgrading is correlated with the trade-weighted average rate of Southern catch-up.
\end{abstract}

Susan Chun Zhu

Department of Economics

University of Toronto

150 St. George Street

Toronto, Ontario

Canada, M5S 3G7
Daniel Trefler

Canadian Institute for Advanced Research (CIAR)

University of Toronto

and NBER 
The trade-and-wages debate has settled comfortably into what Sherlock Holmes might have called 'the $20 \%$ solution.' Using a variety of methodologies, many researchers have demonstrated that international trade accounts for no more than a fifth of the rising inequality experienced by the United States in the last two decades e.g., Feenstra and Hanson (1996a), Borjas et al. (1997), and Baldwin and Cain (2000). As American academic interest in the debate wanes, it is easy to forget that the trade-and-wages debate does not stop at the U.S. border. As some of the demonstrators in Geneva, Seattle, and Québec City remind us, rising inequality is an issue of profound importance to the low- and middle-income countries that constitute the 'South.' This Southern incarnation of the trade-and-wages debate poses difficult challenges for international trade economists wedded to general equilibrium reasoning. Their workhorse general equilibrium model dishes up bland fare for a Southern palate, namely, the Stolper-Samuelson theorem. The theorem states that globalization raises the demand for unskilled Southern labor, thereby reducing inequality in Southern countries. Unfortunately, this prediction is not borne out by the data.

For example, consider the Deininger and Squire (1996) inequality database. It has 29 developing and newly industrialized countries with non-missing data on the change in Gini coefficients over the 1980s. Of these 29 countries, 16 experienced rising inequality, 12 experienced falling inequality, and 1 experienced no change in inequality. This roughly even split between rising and falling inequality illustrates just how complex is the evolution of Southern inequality

While this complexity calls for an alternative to Stolper-Samuelson reasoning, it offers no guidance as to what that alternative might be. For example, there is effectively a zero corre- 
lation between changes in inequality and per capita GDP. This leaves us with a frustrating problem. If the hallmark of international trade theory is general equilibrium reasoning and if the Stolper-Samuelson theorem is out of the picture, then what can international trade theory contribute to our understanding of Southern inequality? Figure 1 hints at a possible answer. For our 29 developing and newly industrialized countries, it plots the growth in inequality against contemporaneous growth in exports. Given the uniqueness of the East Asian experience, we break out countries into two groups, East Asia and 'Other.' The correlations for both groups are positive and very strong. The $R^{2}$ is 0.50 for East Asia and 0.59 for the other countries. These positive correlations are neither trivial nor obvious. Indeed, the Stolper-Samuelson logic predicts a negative relationship.

Of course, one does not want to put too much stock in figure 1. Both the inequality and trade data are permeated with measurement errors. One also does not want to impute causality to the displayed relationship: the results could be driven by any number of omitted factors such as levels of openness, coincidental timing of trade reforms, and differences in domestic re-distributive systems. Notwithstanding these concerns, the figure suggests that general equilibrium trade linkages across countries play at least some role in the complex evolution of Southern inequality.

To explore this role we develop a model in which the correlation between trade and inequality is driven by Southern productivity catch-up. To this end we marry the Dornbusch et al. (1980) model of Heckscher-Ohlin trade with the Dornbusch et al. (1977) model of Ricardian trade. The former allows us to discuss rising wage inequality between skilled and unskilled labor. The latter allows us to discuss international technology differences and 
Southern productivity catch-up.

The intellectual inspiration for our modelling is an elegant observation by Feenstra and Hanson (1996a) that appeared in a Bhagwati festschrift. Feenstra and Hanson point out that U.S. capital investments into Mexico pave the way for the United States to outsource its least skill-intensive goods to Mexico. Since these goods are highly skill intensive by Mexican standards, outsourcing raises the relative demand for skills in both Mexico and the United States. This in turn increases the level of inequality in both regions. The model thus overturns the Stolper-Samuelson prediction and replaces it with a result in which foreign direct investment raises inequality in both Mexico and the United States.

In the model we will be presenting, there is no foreign direct investment. Instead, we consider a general form of Southern catch-up that goes beyond physical capital accumulation. The historical record on growth makes it clear that catching up involves far more than just physical capital accumulation. ${ }^{1}$ In this general setting we replicate and extend the Feenstra and Hanson result. We then show that the faster is a Southern country's rate of catch-up, the greater will be its rates of both inequality growth and export growth. Crosscountry differences in catch-up among Southern countries will therefore generate a positive correlation between changes in inequality and growth in exports. That is, it will generate the pattern illustrated in figure 1.

Note that in replicating and extending the Feenstra and Hanson result, we use a model that incorporates important features absent from their framework. These include (1) Ri-

\footnotetext{
${ }^{1}$ Without any pretensions to comprehensiveness, see for example Schultz (1960) on human capital accumulation, Gerschenkron (1962) on the advantages of being a late-comer, and Acemoglu et al. (2000) on institutions.
} 
cardian sources of comparative advantage, (2) richer general equilibrium feedbacks through the trade balance, (3) substitution in production between skilled and unskilled labor, and (4) skill biased technical change. The latter has recently been advanced as an important fact about the South (Berman and Machin 2000). Together these modelling innovations serve to enrich the general equilibrium feedbacks between trade and inequality.

While our paper is almost exclusively theoretical, in the penultimate section we provide a rudimentary empirical analysis based on our model. We examine the determinants of skill upgrading for all 28 ISIC manufacturing industries operating in 18 developing and newly industrialized countries. For each industry in each country, we measure 'catch-up' as domestic labor productivity growth relative to the trade-weighted average of foreign labor productivity growth. We include this catch-up variable in the type of skill-upgrading equation that has become standard in U.S. applications (e.g., Berman et al. 1994, Feenstra and Hanson 1996a, 1996b, 1999, Autor et. al. 1998, Goldin and Katz 1998), but not in Southern applications. We find that our measure of catch-up is indeed an important determinant of skill upgrading. This provides at least some support for our claim that Southern catch-up, via skill upgrading, has generated a positive correlation between increases in inequality and exports, just as in figure 1 .

The paper is organized as follows. Sections 1-3 set up the model. Sections 4-5 derive the core results on catch-up, trade and inequality. The remaining sections deal with refinements of our notion of catch-up (section 6), the relation of our work to Feenstra and Hanson (1996a) (section 7), implications for real income and welfare in the North and South (section 8), and a rudimentary empirical investigation (section 9). Section 10 concludes. 


\section{The Setup}

We follow the Dornbusch et al. (1980) setup as closely as possible. There are 2 regions, North $(N)$ and South $(S)$. There are 2 factors, unskilled labor $(L)$ and skilled labor $(H)$. There is a continuum of goods indexed by $z$ with $0 \leq z \leq 1$. Production functions are regularly neoclassical, displaying strict quasi-concavity, constant returns to scale, and continuous derivatives. In addition, there are no factor intensity reversals. This last assumption implies that we can identify larger $z$ with greater skill intensity. Goods markets are perfectly competitive and profits are zero in equilibrium. There are no international barriers to trade in goods. Factor markets are perfectly competitive and clear domestically. Consumers have identical Cobb-Douglas preferences. Finally, international trade is balanced. This setup is identical to Dornbusch et al. (1980), except for the presence of international technology differences.

There are 2 sources of comparative advantage in our model. The first is endowments. Let $w_{f i}$ be the wage of factor $f(=L, H)$ in region $i(=N, S)$. Let $w_{i} \equiv w_{H i} / w_{L i}$ be the wage of skilled labor relative to that of unskilled labor. As in Dornbusch et al. (1980), we assume that the North is sufficiently skill abundant so that $w_{N}<w_{S}$. This implies that the North has a comparative advantage in skill-intensive goods. The second source of comparative advantage - which does not appear in Dornbusch et al. (1980), but is the focus of Dornbusch et al. (1977) - is Ricardian international technology differences. We assume that these differences confer a comparative advantage to the North in skill-intensive goods. That is, the North has relatively lower marginal costs for producing relatively more skill-intensive goods. To express this mathematically, let $C_{i}\left(w_{H i}, w_{L i}, z\right)$ be the unit cost 
function for producing good $z$ in region $i$. We assume that

$$
\frac{\partial C_{N}(\cdot, \cdot, z) / C_{S}(\cdot, \cdot, z)}{\partial z} \leq 0 \text { for all } z
$$

With two goods $\left(z_{1}>z_{2}\right)$ inequality $(1)$ can be written as $C_{N}\left(\cdot, \cdot, z_{1}\right) / C_{N}\left(\cdot, \cdot, z_{2}\right) \leq$ $C_{S}\left(\cdot, \cdot, z_{1}\right) / C_{S}\left(\cdot, \cdot, z_{2}\right)$. That is, it is an inequality involving 2 ratios of marginal costs, just as in Ricardian textbook explanations of trade. The only difference is that with 2 types of labor something must be said about factor prices. Inequality (1) compares $C_{N}$ and $C_{S}$ at any common set of factor prices.

Lemma 1 establishes that our 2 sources of comparative advantage work in the same direction and can be neatly integrated into a single model. All proofs appear in the appendix.

Lemma 1. Endowments-based comparative advantage $\left(w_{N}<w_{S}\right)$ and Ricardian-based comparative advantage ( inequality 1) together imply

$$
\frac{\partial}{\partial z} \frac{C_{N}\left(w_{H N}, w_{L N}, z\right)}{C_{S}\left(w_{H S}, w_{L S}, z\right)}<0
$$

for all $\left(w_{H S}, w_{L S}, w_{H N}, w_{L N}\right)$ such that $w_{N}<w_{S}$ and for all $z$. That is, the North has a comparative advantage in skill-intensive goods.

Given lemma 1 it is easy to show that for each factor price quadruplet satisfying $w_{N}<$ $w_{S}$, there is a unique $\bar{z}$ on the interior of the unit interval such that $C_{N}\left(w_{H N}, w_{L N}, \bar{z}\right)=$ $C_{S}\left(w_{H S}, w_{L S}, \bar{z}\right)$. (See the proof of lemma 1.) It follows that $C_{N}\left(w_{H N}, w_{L N}, z\right)$ is below $C_{S}\left(w_{H S}, w_{L S}, z\right)$ if and only if $z>\bar{z}$. This is illustrated in figure 2. (Note that we do 
not know anything about the individual $C_{i}$, not even monotonicity. This is because the individual $C_{i}$ deal with absolute advantage.)

It follows that even though we have an additional (Ricardian) source of comparative advantage that does not appear in Dornbusch et al. (1980), we can still expect a similar characterization of equilibrium. Specifically, there is a 'competitive margin' $\bar{z}$ such that the North produces all goods $z>\bar{z}$ and the South produces all goods $z<\bar{z}$. That is, the North specializes in the most skill-intensive goods.

\section{Equilibrium Conditions}

To keep the notation simple, for the remainder of the paper we suppress the $w_{H i}$ and $w_{L i}$ as arguments of functions whenever possible. We emphasize that this is a notational convenience: we are making no assumptions about substitution possibilities in production. Let $P_{i}(z)$ be the competitive price for good $z$ produced in region $i$. $\bar{z}$ is defined by

$$
P_{N}(\bar{z})=P_{S}(\bar{z})
$$

By the zero-profit condition, equation (3) is just the figure 2 crossing condition. Let $Y_{i}$ be national income in region $i$. Preferences are given by the Cobb-Douglas utility function $U=\int_{0}^{1} \alpha(z) \ln x(z) d z$ where for each $z, \alpha(z)$ is a budget share and $x(z)$ is a quantity 
consumed. ${ }^{2}$ Worldwide demand is

$$
x(z)=\alpha(z) \frac{Y_{N}+Y_{S}}{P_{i}(z)}
$$

where $i=N$ for $z>\bar{z}$ and $i=S$ for $z<\bar{z}$.

Let $L_{i}$ and $H_{i}$ be region $i$ 's endowments of unskilled and skilled labor, respectively. Let $L_{i}(z)$ and $H_{i}(z)$ be the amount of unskilled and skilled labor, respectively, needed to produce one unit of good $z$ in region $i$. To keep the reader clear, we repeat that these are unit demands (not total demands) and that they depend on $w_{H i}$ and $w_{L i}$ (which are suppressed). Define $h_{i} \equiv H_{i} / L_{i}$ and $h_{i}(z) \equiv H_{i}(z) / L_{i}(z)$. Market clearing for Southern skilled labor is given by

$$
\int_{0}^{\bar{z}} x(z) H_{S}(z) d z=H_{S}
$$

Following Dornbusch et al. (1980), we can combine the zero profit condition $P_{i}(z)=$ $w_{L i} L_{i}(z)+w_{H i} H_{i}(z)$ with equations such as (5) to obtain 2 equations that summarize factor market clearing. To this end, define $S(\bar{z}) \equiv \int_{0}^{\bar{z}}\left[x(z) H_{S}(z) / H_{S}\right] d z-\int_{0}^{\bar{z}}\left[x(z) L_{S}(z) / L_{S}\right] d z$. $S(\bar{z})$ is the excess demand for skilled labor relative to unskilled labor. With some manipulation, $S(\bar{z})=0$ may be written as $^{3}$

\footnotetext{
${ }^{2}$ Preliminary analysis suggests that our results go through with CES preferences. Unfortunately, CES preferences introduce additional general equilibrium feedbacks that obscure the main point. We have thus not pursued this line of inquiry in any depth.

${ }^{3}$ Consider a $z \in[0, \bar{z}]$. From equation (4) and zero profits, $x(z)=\left(Y_{N}+Y_{S}\right) \alpha(z) /\left[w_{L S} L_{S}(z)+\right.$ $\left.w_{H S} H_{S}(z)\right]=\frac{Y_{N}+Y_{S}}{w_{L S}} \alpha(z) \frac{1 / L_{S}(z)}{1+w_{S} h_{S}(z)}$. Hence, $\int_{0}^{\bar{z}}\left[x(z) H_{S}(z) / H_{S}\right] d z=\frac{Y_{N}+Y_{S}}{w_{L S} H_{S}} \int_{0}^{\bar{z}} \alpha(z) \frac{h_{S}(z)}{1+w_{S} h_{S}(z)} d z$. Likewise, $\int_{0}^{\bar{z}}\left[x(z) L_{S}(z) / L_{S}\right] d z=\frac{Y_{N}+Y_{S}}{w_{L S} H_{S}} \int_{0}^{\bar{z}} \alpha(z) \frac{h_{S}}{1+w_{S} h_{S}(z)} d z$. Plugging these into the definition of $S(\bar{z})$ yields equation (6).
} 


$$
S(\bar{z})=\frac{Y_{N}+Y_{S}}{w_{L S} H_{S}} \int_{0}^{\bar{z}} \alpha(z) \frac{h_{S}(z)-h_{S}}{1+w_{S} h_{S}(z)} d z=0 .
$$

Likewise, the corresponding Northern factor market clearing condition $N(\bar{z}) \equiv \int_{\bar{z}}^{1}\left[x(z) H_{N}(z) /\right.$ $\left.H_{N}\right] d z-\int_{\bar{z}}^{1}\left[x(z) L_{N}(z) / L_{N}\right] d z=0$ may be written as

$$
N(\bar{z})=\frac{Y_{N}+Y_{S}}{w_{L N} H_{N}} \int_{\bar{z}}^{1} \alpha(z) \frac{h_{N}(z)-h_{N}}{1+w_{N} h_{N}(z)} d z=0 .
$$

Define the trade balance as the value of Southern imports divided by the value of Northern imports: $B(\bar{z}) \equiv\left(Y_{S} \int_{\bar{z}}^{1} \alpha(z) d z\right) /\left(Y_{N} \int_{0}^{\bar{z}} \alpha(z) d z\right)$. Substituting equation (3) and the zero profit condition into the balance-of-trade condition $B(\bar{z})=1$ yields $^{4}$

$$
B(\bar{z})=\frac{L_{S}}{L_{N}} \cdot \frac{L_{N}(\bar{z})}{L_{S}(\bar{z})} \cdot \frac{1+w_{S} h_{S}}{1+w_{N} h_{N}} \cdot \frac{1+w_{N} h_{N}(\bar{z})}{1+w_{S} h_{S}(\bar{z})} \cdot \frac{\int_{\bar{z}}^{1} \alpha(z) d z}{\int_{0}^{\bar{z}} \alpha(z) d z}=1 .
$$

Following Dornbusch et al. (1980) and as detailed in appendix A.2, the search for a competitive equilibrium can be reduced to the search for a triplet $\left(w_{N}, w_{S}, \bar{z}\right)$ that solves equations (6)-(8). Lemmas 3-4 of appendix A.2 establish that there exists a unique equilibrium. Further, if $h_{N} / h_{S}$ is sufficiently large then $w_{N}<w_{S}$ will be a feature of the unique equilibrium. This completes the set-up of the model and the characterization of the unique

\footnotetext{
${ }^{4}$ By zero profits, $P_{i}(\bar{z})=w_{L i} L_{i}(\bar{z})\left(1+w_{i} h_{i}(\bar{z})\right)$. Plugging this into $P_{N}(\bar{z})=P_{S}(\bar{z})$ yields

$$
\frac{w_{L S}}{w_{L N}}=\frac{L_{N}(\bar{z})}{L_{S}(\bar{z})} \cdot \frac{1+w_{N} h_{N}(\bar{z})}{1+w_{S} h_{S}(\bar{z})} .
$$
}

Using $Y_{i}=w_{L i} L_{i}\left(1+w_{i} h_{i}\right)$ and the previous equation yields

$$
\frac{Y_{S}}{Y_{N}}=\frac{L_{S}}{L_{N}} \cdot \frac{L_{N}(\bar{z})}{L_{S}(\bar{z})} \cdot \frac{1+w_{S} h_{S}}{1+w_{N} h_{N}} \cdot \frac{1+w_{N} h_{N}(\bar{z})}{1+w_{S} h_{S}(\bar{z})}
$$

from which equation (8) follows. 
equilibrium.

\section{Technical Change and the Definition of Southern Catch-Up}

Given the complexity of the model, including its 2 sources of comparative advantage, we make several simplifying assumptions about the nature of technical change. For one, we assume that it involves cost-cutting process innovation rather than product innovation. This is in the spirit of a model geared to Southern technology catch-up. Product innovation is taken up in Zhu (2001). Also, we assume that technical change is exogenous and uses no real resources. Endogenizing technical change offers important insights (Acemoglu 1998, 2000), but is not our focus here.

We are interested in comparative static exercises involving technical change. Let $t$ denote the state of technology. Note that our model is static so that $t$ is not an index of time. For

each $t$, there is a unique equilibrium and unique equilibrium outcomes $w_{N}(t), w_{S}(t)$, and $\bar{z}(t)$. Re-write factor demands and unit costs in a way that highlights their dependence on

$t$. Thus the $H_{i}(z, t)$ and $L_{i}(z, t)$ are factor demands per unit of $z$ and the $C_{i}\left(w_{H i}, w_{L i}, z, t\right)$ are costs per unit of $z$. We assume that these functions are differentiable in $t$ and use the convention that the $C_{i}\left(w_{H i}, w_{L i}, z, t\right)$ are non-increasing in $t$ i.e., technical change never increases unit costs.

The natural measure of productivity growth in the production of good $z$ in region $i$ is $-\partial \ln C_{i}\left(w_{H i}, w_{L i}, z, t\right) / \partial t$. This is just the dual of the Solow residual. We will write that 
the South is 'catching up' if

$$
\gamma(t) \equiv \frac{\partial \ln C_{N}\left(w_{H N}, w_{L N}, \bar{z}, t\right)}{\partial t}-\frac{\partial \ln C_{S}\left(w_{H S}, w_{L S}, \bar{z}, t\right)}{\partial t}>0
$$

Equation (9) states that the South is catching up if, for good $\bar{z}=\bar{z}(t)$, Southern productivity rises relative to Northern productivity. We will write that the South is 'falling behind' if $\gamma(t)<0 .^{5}$

There are two problems with our definition of Southern catch-up that are more apparent than real. First, we have defined Southern catch-up only in terms of productivity growth for good $\bar{z}(t)$. It would be more desirable to define it in terms applicable to all Southern goods. However, doing so offers no additional insights. Further, it adds considerably to the notational burden because of Hulten's (1973) 'path dependence' problem. This point is developed in section 6. Expositional simplicity thus calls for initially defining Southern catch-up in terms of good $\bar{z}(t)$. Second, it would be nice to express technical change in terms of a more primitive parameterization. This is done in section 6 . There it is shown that there is a $1: 1$ relationship between primitive parameterizations of Southern catch-up and the more interpretable parameterization of equation (9). Expositional clarity thus calls for using $\gamma(t)$.

Finally, in what follows we suppress the technology argument $t$ in $w_{N}(t), w_{S}(t), \bar{z}(t)$, and $\gamma(t)$. This completes the definition of Southern catch-up.

\footnotetext{
${ }^{5}$ It might be helpful to some readers if we were more careful with the notation in equation (9). Throughout this paper, $\partial C_{i}\left(w_{H i}, w_{L i}, \bar{z}, t\right) / \partial t$ denotes the derivative of $C_{i}\left(w_{H i}, w_{L i}, z, t\right)$ with respect to its fourth argument $(t)$ and evaluated at $\left(w_{H i}, w_{L i}, z\right)=\left(w_{H i}(t), w_{L i}(t), \bar{z}(t)\right)$. Re-stated, the derivative holds factor prices and $\bar{z}(t)$ constant at their initial equilibrium values.
} 


\section{Neutral Technical Change}

In order to make the main results as clear as possible we begin by assuming that Southern catch-up involves Hicks-neutral technical change. Skill biased technical change is dealt with in the next section. Recall that $w_{i}$ is the wage of skilled labor relative to unskilled labor in region $i(=N, S) . w_{N}$ and $w_{S}$ will be our measures of inequality. ${ }^{6}$ Theorem 1 relates Southern catch-up to changing patterns of trade and inequality.

Theorem 1. Assume that technical change is Hicks neutral.

(1) If the South is catching up $(\gamma>0)$ then $d w_{N} / d t>0, d w_{S} / d t>0$, and $d \bar{z} / d t>0$. That is, wage inequality widens in both regions and production of the least skill-intensive Northern goods migrates South.

(2) If the South is falling behind $(\gamma<0)$ then $d w_{N} / d t<0, d w_{S} / d t<0$, and $d \bar{z} / d t<0$. That is, wage inequality falls in both regions and production of the most skill-intensive Southern goods migrates North.

The way to start thinking about theorem 1 is in terms of the Feenstra and Hanson (1996a) sorting mechanism. Referring to figure 2, Southern catch-up leads to a fall in the $C_{S}\left(w_{H S}, w_{L S}, z, t\right)$ schedule relative to the $C_{N}\left(w_{H N}, w_{L N}, z, t\right)$ schedule. This leads to a rise in $\bar{z}$. In the North, the rise in $\bar{z}$ eliminates the most unskilled-intensive jobs, thereby lowering the demand for unskilled labor. Northern inequality rises. In the South, the rise in $\bar{z}$ creates jobs that are more skill intensive than any existing Southern jobs, thereby raising

\footnotetext{
${ }^{6}$ With Cobb-Douglas preferences, a one precent rise in wages leads to a one percent rise in the consumption of each good. Therefore, $w_{i}$ is also a consumption-based measure of inequality. See Attanasio and Davis (1996) for a discussion of such measures.
} 
the demand for skilled labor. Southern inequality rises. Of course, this Feenstra-Hanson mechanism is only part of the story. Neutral technical change has general equilibrium effects on factor prices that lead to further shifts in the figure 2 cost curves. These general equilibrium effects are remarkably rich. To describe them simply, in the next few paragraphs we assume that there is no technical change in the North.

At fixed $\left(w_{N}, w_{S}\right)$, Southern catch-up makes the South absolutely more productive. This leads to positive profits in the South. Competition for labor among Southern firms raises the relative wage of Southern workers $\left(w_{L S} / w_{L N}\right.$ and $w_{H S} / w_{H N}$ rise). Rising income leads the South to import more. The result is a negative Southern trade balance. To eliminate the trade imbalance the South increases its supply of goods and reduces its demand for Northern goods. Both changes are facilitated by a rise in $\bar{z}$.

Now allow $\left(w_{N}, w_{S}\right)$ to change. The rise in $\bar{z}$ eliminates the trade imbalance, but creates Southern excess demand for skilled labor relative to unskilled labor. Rising $w_{S}$ eliminates this excess demand in 2 ways. First, it leads to a within-good substitution away from skilled labor. Second, it increases the relative price of skill-intensive goods which leads to a between-good reallocation toward the South's unskilled-intensive goods. Together, these 2 mechanisms clear Southern labor markets. Adjustment in the North proceeds along similar lines. $^{7}$

\footnotetext{
${ }^{7}$ It is easy to prove that the rise in $w_{S}$ increases the relative price of skill-intensive goods. Let $\theta_{H S}(z) \equiv$ $w_{H S} H_{S}(z) /\left[w_{H S} H_{S}(z)+w_{L S} L_{S}(z)\right]$ be the cost share of skilled workers in the production of good $z$ in the South. Consider two Southern goods $z_{1}$ and $z_{2}$. Differentiating the relative price of the two goods with respect to the relative wage yields $d\left[P_{S}\left(z_{2}\right) / P_{S}\left(z_{1}\right)\right] / d w_{S}=\theta_{H S}\left(z_{2}\right)-\theta_{H S}\left(z_{1}\right)$ which is positive if and only if $z_{2}>z_{1}$.
} 
The equilibrating mechanisms set off by Southern catch-up are rich in general equilibrium feedbacks. There is a between-country reallocation of goods from the North to the South, a within-country reallocation of goods toward unskilled-intensive goods, and a within-good substitution of unskilled labor for skilled labor. The mechanisms are facilitated by equilibrating movements in the trade balance and relative prices.

We next turn to the cross-country correlation between $d w_{S} / d t$ and $d \bar{z} / d t$ illustrated in figure 1. Theorem 2 provides an explanation of the correlation.

Theorem 2. $d w_{N} / d t, d w_{S} / d t$, and $d \bar{z} / d t$ are increasing in the rate of Southern catch-up $(\gamma)$. In particular, the faster is Southern catch-up, the greater is the growth in Southern inequality and Southern exports.

Generalizing to the multi-country world of figure 1, theorem 2 suggests the following. Southern countries with high rates of catch-up will have high rates of inequality growth (large $d w_{S} / d t$ ) and high rates of export growth (large $d \bar{z} / d t$ ). Thus, differences in the rate of catch-up among Southern countries will generate a positive cross-country correlation between rising inequality and export growth. This is exactly as depicted in figure 1. Note that the theorem does not require Hicks-neutral technical change.

On a technical note, $d \bar{z} / t$ is not quite the same as the growth in the real value of exports. While we can also show that growth in the real value of Southern exports is increasing in the rate of Southern catch-up (see theorem 5 below), this requires a bit more work. The problem is that one needs to introduce price deflators in order to discuss real exports. We therefore postpone presentation of this result until we define deflators in section 8 below. 
To summarize, theorems 1-2 establish that figure 1 as well as rising inequality in both the North and the South are consistent with an almost-standard trade model featuring a combination of Ricardian and Heckscher-Ohlin elements. Theorem 1 also shows that skill biased technical change is not necessary for rising inequality. Even with neutral technical change, Southern catch-up can raise wage inequality in both regions.

\section{Skill-Biased Technical Change}

Of course, skill biased technical change is likely the single most important contributor to rising inequality in the North (e.g., Katz and Murphy 1992, Autor et al. 1998, and Berman et al. 1998). We therefore need to ensure that our trade-based explanation of North-South inequality spillovers is consistent with Northern skill biased technical change.

We begin with the simplifying assumption that the rate of skill biased technical change is the same across all goods within a region. ${ }^{8}$

Assumption 1. There exist $\rho_{N}(t)$ and $\rho_{S}(t)$ such that

$$
\frac{\partial}{\partial t}\left(\ln \frac{H_{i}(z, t)}{L_{i}(z, t)}\right)=\rho_{i}(t) \text { for all } z \text { and for } i=N, S
$$

We know from Berman and Machin (2000) that the South has experienced skill upgrading so that skill biased technical change in the South is likely also relevant. Indeed, it is their research that has motivated much of the analysis of this section. Note that assumption 1

\footnotetext{
${ }^{8}$ Recalling that the factor price arguments of $H_{i}(z, t)$ are suppressed, by $\partial \ln H_{i}(z, t) / \partial t$ we will mean the derivative of $\ln H_{i}\left(w_{H i}, w_{L i}, z, t\right)$ with respect to its fourth argument $(t)$ and evaluated at $\left(w_{H i}, w_{L i}\right)=$ $\left(w_{H i}(t), w_{L i}(t)\right)$. Re-stated, the derivative holds factor prices constant at their initial equilibrium values. Likewise for $d \ln L_{i}(z, t) / d t$.
} 
is made for expositional ease in characterizing skill biased technical change and is otherwise entirely unnecessary. ${ }^{9}$ In what follows, the dependence of the $\rho_{i}$ on $t$ is dropped.

Under assumption $1, d w_{N} / d t, d w_{S} / d t$, and $d \bar{z} / d t$ are linear functions of $\gamma, \rho_{N}$, and $\rho_{S}$. Specifically, letting $x$ index $w_{N}, w_{S}$, and $\bar{z}$,

$$
\frac{d x}{d t}=\left(\gamma-a_{x} \rho_{N}-b_{x} \rho_{S}\right) c_{x}, \quad x=w_{N}, w_{S}, \bar{z}
$$

where $a_{x}, b_{x}$, and $c_{x}$ are functions of preferences and the level of technology, but are not functions of the technology change parameters $\left(\gamma, \rho_{N}, \rho_{S}\right)$. The proof of linearity is not complicated. (See appendix A.4.) The difficult part is the signing of the $a_{x}, b_{x}$, and $c_{x}$. Remarkably, all nine parameters can be signed.

Lemma 2. Let assumption 1 hold. Then (1) $a_{w_{S}}=a_{\bar{z}}>0, a_{w_{N}}<0$, (2) $b_{w_{N}}=b_{\bar{z}}>0$, $b_{w_{S}}<0$, and $(3) c_{w_{N}}>0, c_{w_{S}}>0, c_{\bar{z}}>0$

Part (3) states that the $d x / d t$ are increasing in $\gamma$. That is, theorem 2 holds with or without skill biased technical change. The generalization of theorem 1 to the case of skill biased technical change is straightforward and appears in theorem 3 below. However, it is much easier to first explain theorem 3 graphically.

Figure 3 plots the $d x / d t=0$ lines in $\left(\gamma, \rho_{N}\right)$-space for the case where $\rho_{S}=0$. From equation (10), the $d x / d t=0$ lines are rays through the origin with slope $a_{x}$. If follows from lemma $2\left(a_{w_{S}}=a_{\bar{z}}>0\right)$ that the $d w_{S} / d t=0$ and $d \bar{z} / d t=0$ lines coincide and are upward

\footnotetext{
${ }^{9}$ Without assumption $1, \rho_{N}(t)$ is replaced throughout by $b_{2}$ of appendix equation $(26)$ and $\rho_{S}(t)$ is replaced throughout by $b_{3}$ of appendix equation (27). $b_{2}$ and $b_{3}$ are weighted averages across $z$ of the rates of skill biased technical change. The generality obtained by eliminating assumption 1 is more than offset by the notational burden of equations (26) and (27).
} 
sloping. Above these lines, Southern catch-up $\gamma$ is strong enough that $d w_{S} / d t$ and $d \bar{z} / d t$ are both positive. Why do these lines slope upward? Northern skill biased technical change is factor augmenting and so increases the effective supply of Northern unskilled labor. This excess supply is absorbed in part by a fall in $\bar{z}$. This means that for $\rho_{N}>0$, Southern catch-up $(\gamma>0)$ is no longer sufficient to ensure $d \bar{z} / d t>0$. Southern catch-up must not only be present, it must be strong enough to offset the effects of Northern skill biased technical change.

Turning to Northern inequality, lemma $2\left(a_{w_{N}}<0\right)$ and equation (10) imply that the $d w_{N} / d t=0$ line is downward sloping. Above this line, Southern catch-up $\gamma$ is strong enough that $d w_{N} / d t$ is positive. This line slopes downward because Northern skilled biased technical change is an independent source of rising Northern inequality. Thus, even if there were no Southern catch-up $(\gamma=0)$, the North would experience rising inequality whenever $\rho_{N}>0$.

Figure 3 can be completely generalized. To allow for $\rho_{S} \neq 0$, simply appeal to equation (10) and part (2) of lemma 2 to establish that if $\rho_{S}$ is positive then the $d w_{N} / d t=0$ and $d \bar{z} / d t=0$ curves shift up by the same amount and the $d w_{S} / d t=0$ curve shifts down. To draw a figure in $\left(\gamma, \rho_{S}\right)$-space, note that the symmetry of parts (1) and (2) of lemma 2 establish that such a figure can be derived from figure 3 by interchanging all the references to North and South.

This discussion is formalized in the next theorem which is the generalization of theorem 1 to the case of skill biased technical change.

Theorem 3. Under assumption 1 there exist linear functions $f_{\bar{z}}\left(\rho_{N}, \rho_{S}\right)$ and $f_{w}\left(\rho_{N}, \rho_{S}\right)$ such that 
(1) $\gamma>f_{\bar{z}}\left(\rho_{N}, \rho_{S}\right) \Leftrightarrow d \bar{z} / d t>0 . f_{\bar{z}}$ is the rate of Southern catch-up that is necessary and sufficient for the least skill-intensive Northern goods to migrate South. Further, $f_{\bar{z}}=a_{\bar{z}} \rho_{N}+b_{\bar{z}} \rho_{S}$ so that this rate $f_{\bar{z}}$ depends positively on the rates of skill biased technical change $\rho_{N}$ and $\rho_{S}$.

(2) $\gamma>f_{w}\left(\rho_{N}, \rho_{S}\right) \Leftrightarrow\left\{d w_{N} / d t>0\right.$ and $\left.d w_{S} / d t>0\right\} . f_{w}$ is the rate of Southern catchup that is necessary and sufficient for inequality to rise in both regions. Further, $f_{w}=\max \left(a_{w_{N}} \rho_{N}+b_{w_{N}} \rho_{S}, a_{w_{S}} \rho_{N}+b_{w_{S}} \rho_{S}\right)$.

Theorems 2-3, lemma 2, and the expressions for the $a_{x}, b_{x}$, and $c_{x}$ in the proof of lemma 2, completely characterize the relationship between Southern catch-up, international trade, and inequality.

\section{Some Notes on the Interpretation of $\gamma$}

This section develops some details about the Southern catch-up parameter $\gamma$. The section can be skipped without loss of continuity. Define $\gamma_{H} \equiv \partial \ln H_{N}(\bar{z}, t) / \partial t-\partial \ln H_{S}(\bar{z}, t) / \partial t .{ }^{10}$ Also, let $\bar{\theta}_{L i}$ be unskilled labor's cost share for good $\bar{z}, i=N, S$. Then ${ }^{11}$

$$
\gamma=\gamma_{H}-\bar{\theta}_{L N} \rho_{N}+\bar{\theta}_{L S} \rho_{S}
$$

\footnotetext{
${ }^{10} \mathrm{By} \partial \ln H_{i}(\bar{z}, t) / \partial t$ we mean the derivative of $\ln H_{i}\left(w_{H i}, w_{L i}, z, t\right)$ with respect to its fourth argument $(t)$ and evaluated at $\left(w_{H i}, w_{L i}, z\right)=\left(w_{H i}(t), w_{L i}(t), z(t)\right)$.

${ }^{11}$ From the definition of cost shares, $\bar{\theta}_{L i} \equiv w_{L i} L_{i}(\bar{z}, t) / C_{i}\left(w_{H i}, w_{L i}, \bar{z}, t\right)$. Since $\frac{\partial}{\partial t} \ln C_{i}\left(w_{H i}, w_{L i}, \bar{z}, t\right)=$ $\bar{\theta}_{L i} \frac{\partial}{\partial t} \ln L_{i}(\bar{z}, t)+\left(1-\bar{\theta}_{L i}\right) \frac{\partial}{\partial t} \ln H_{i}(\bar{z}, t)$, assumption 1 implies that $\frac{\partial}{\partial t} \ln C_{i}\left(w_{H i}, w_{L i}, \bar{z}, t\right)=\frac{\partial}{\partial t} \ln H_{i}(\bar{z}, t)-$ $\bar{\theta}_{L i} \rho_{i}$. Equation (11) follows from this expression together with equation (9) and the definition of $\gamma_{H}$.
} 
Equation (11) reveals three things about $\gamma$. First, in the absence of skill biased technical change $\left(\rho_{N}=\rho_{S}=0\right), \gamma=\gamma_{H}$ so that our definition of Southern catch-up reduces to $\gamma_{H}>0$. This is useful in that $\gamma_{H}$ is a more primitive parameterization of technical change than is $\gamma$. Unfortunately, $\gamma_{H}$ is not a particularly informative parameter in the presence of skill biased technical change. Second, since $\gamma$ depends on the $\rho_{i}$ whereas $\gamma_{H}$ does not, a mathematically expedient parameterization of our problem is in terms of the triplet $\left(\gamma_{H}, \rho_{N}, \rho_{S}\right)$. However, there is a trivial and invertible linear mapping between $\left(\gamma_{H}, \rho_{N}, \rho_{S}\right)$ and $\left(\gamma, \rho_{N}, \rho_{S}\right)$ so that we are free to forego the mathematically expedient parameterization $\left(\gamma_{H}, \rho_{N}, \rho_{S}\right)$ in favor of the economically meaningful parameterization $\left(\gamma, \rho_{N}, \rho_{S}\right)$.

Third, $\gamma$ depends on cost shares $\bar{\theta}_{L i}$. This reflects the usual problem that with nonneutral technical change, productivity indexes depend on the choice of inputs used in the base period e.g., Hulten (1973). To see this visually, consider figure 4 which portrays the special case where skill biased technical change rotates this isoquant inwards around the point $\left(L^{\prime}, H^{\prime}\right)$. The distance between the two isoquants along a ray from the origin is related to several commonly used productivity measures. This distance shrinks as $L$ grows. By implication, the measure of productivity depends on unskilled labor's cost share. Extending this logic to comparisons between goods with different unskilled labor shares explains the dependence of Southern catch-up on factor cost shares.

This factor share complication creates a question of how to define Southern catch-up for all goods $z$ and not just for $\bar{z}$. This is conceptually easy to do, but involves considerable additional notation without offering any deep additional insights. ${ }^{12}$ The interested reader

\footnotetext{
${ }^{12}$ Conceptually, Southern catch-up is simple to define for all $z$. Assume that $\frac{\partial}{\partial t} \ln H_{N}(z, t) / H_{S}(z, t)$ is independent of $z$. Then Southern catch-up may be defined as the set of triplets $\left(\gamma_{H}, \rho_{N}, \rho_{S}\right)$ for which
} 
is invited to work out these insights by referring to equations (26)-(27) in appendix A.4. We therefore forego generality in favor of expositional simplicity.

\section{Relation to Feenstra and Hanson}

Since we are building on work by Feenstra and Hanson (1996a), it is worthwhile understanding the differences between our work and theirs. In terms of the questions asked, we are both interested in theorem 1 . However, we are also interested in our figure 1 empirical observation and its theorem 2 explanation. In terms of the model used, there are a number of important differences. First, our model combines endowments-based comparative advantage with Ricardian-based comparative advantage. The latter is central to our discussion of technological catch-up. In contrast, Feenstra and Hanson (1996a) do not consider a general form of technological catch-up and in particular do not consider a form that allows for Ricardian-based comparative advantage. (See equation 12 below.) Second, Feenstra and Hanson consider a partial equilibrium model rather than a general equilibrium model. This is natural given their partial equilibrium question, namely, what is the impact of foreign direct investment on skill-upgrading within a single industry? In contrast, we are interested in a general equilibrium question and hence a general equilibrium model of international trade. Such models are closed with a trade-balance condition. As was shown, much of the adjustment in our model takes place via this trade-balance condition.

Third, Feenstra and Hanson assume that skilled and unskilled labor are Leontief or

$\gamma_{H}-\theta_{L N}(z, t) \rho_{N}+\theta_{L S}(z, t) \rho_{S}>0$ for all $z$ where $\theta_{L i}(z, t)$ is unskilled labor's share of costs for good $z$. However, this set is a little messy to write down neatly. Since it involves expressions of the form $\max _{z} \theta_{L i}(z, t)$ and $\min _{z} \theta_{L i}(z, t)$, this messiness also makes it difficult to neatly communicate the information in lemma 2 . 
perfect complements. This makes sense given their question. They are interested in foreign direct investment and so must model capital. To keep things simple in their 3-factor model, they assume that the 2 types of labor are perfect complements. Using obvious notation, their production functions are given by

$$
F_{i}(H, L, K ; z)=A_{i} \min \left(\frac{H}{a_{H}(z)}, \frac{L}{a_{L}(z)}\right)^{1-\theta} K^{\theta}, \quad i=N, S
$$

Clearly, for the purposes of fully explaining rising inequality, flexibly modelling the elasticity of substitution between skilled and unskilled labor is crucial (e.g., Katz and Murphy 1992).

Finally, there are many other differences between their model and ours that are of a more technical nature. (i) Uniqueness of equilibrium plays an important role for any comparative static exercise. As Feenstra and Hanson are careful to note, they obtain uniqueness by assuming that capital's cost share $\theta$ is the same for all $z$. This is a strong assumption. In contrast, our uniqueness falls directly out of the strict quasi-concavity of production and utility functions. Further, they use uniqueness to establish a stability condition that is then used to establish results about relative wages. This puts even more weight on their assumption about capital's cost share. In contrast, we need none of this. (ii) Their international differences in the level of technology (the $A_{i}$ ) are Hicks-neutral. We make no assumptions about the level of international technology differences. (iii) In their production function the $A_{i}$ are independent of $z$. This is the point made at the start of this section that Feenstra and Hanson's international technology differences are a source of Ricardian absolute advantage, but not a source of Ricardian comparative advantage. 


\section{Outstanding Questions}

Southern catch-up has welfare implications that have been hotly contested. For one, the South's terms of trade are expected to deteriorate as faster productivity growth in the export sector reduces export prices relative to import prices. The usual Bhagwati (1958) analysis of immiserizing growth suggests that this may reduce Southern welfare. Another hotly debated question in Northern countries is whether the North has been made worse off as a result of production migrating South. We revisit these issues within the context of our model.

Since we are interested in the case where Southern catch-up and skill biased technical change lead to rising $\bar{z}$ and rising inequality in both regions, we assume that $\gamma, \rho_{N}$ and $\rho_{S}$ are non-negative. This implies that in theorem $3, f_{\bar{z}} \geq f_{w}$. Thus, $\gamma>f_{\bar{z}}\left(\rho_{N}, \rho_{S}\right)$ is necessary and sufficient for rising trade and inequality.

Assumption 2. (1) $\gamma, \rho_{N}$, and $\rho_{S}$ are non-negative. (2) $\gamma>f_{\bar{z}}\left(\rho_{N}, \rho_{S}\right)$. Equivalently, $d w_{N} / d t>0, d w_{S} / d t>0$, and $d \bar{z} / d t>0$. (3) $\partial \ln H_{i}(z, t) / d t$ is non-positive and independent of $z, i=N, S$.

To discuss real income we will need a price index $P$. Part (3) of assumption 2 places restrictions on the variability of individual components of $P$. With Cobb-Douglas preferences, the natural choice of $P$ is the Cobb-Douglas price index. ${ }^{13}$ Then $Y_{i} / P(i=N, S)$ is both real income and a measure of welfare for a representative consumer with income $Y_{i}$. The next theorem answers the questions raised at the start of this section.

\footnotetext{
${ }^{13}$ This is implicitly defined by $\ln P \equiv \int_{0}^{\bar{z}} \alpha(z) \ln P_{S}(z) d z+\int_{\bar{z}}^{1} \alpha(z) \ln P_{N}(z) d z$.
} 
Theorem 4. Let assumptions 1-2 hold. Then

(1) $d\left(Y_{N} / P\right) / d t>0$ and $d\left(Y_{S} / P\right) / d t>0$. That is, real income rises in both the North and the South.

(2) $d\left[P_{N}\left(z^{\prime}\right) / P_{S}(z)\right] / d t>0$ for all pairs $z$ and $z^{\prime}$ with $z<\bar{z}<z^{\prime}$. That is, the South's terms of trade deteriorate and the North's terms of trade improve.

(3) $d\left(Y_{S} / Y_{N}\right) / d t>0$. That is, Southern catch-up reduces the North-South income gap.

Theorem 4 states that even though catch-up leads to a deterioration of the South's terms of trade, the South's real income rises. In Baghwati's terminology, growth is not immiserizing even though it leads to a deterioration of the terms of trade. Theorem 4 also states that the North's real income rises. That is, the income lost by having production migrate South is offset by an improvement in the terms of trade. Thus, theorem 4 at least partly buttresses claims that Southern catch-up is no threat to the North.

Next, we establish a result about the real value of exports. The value of Southern exports is $X_{S} \equiv Y_{N} \int_{0}^{\bar{z}} \alpha(z) d z$ and the real value of Southern exports is $X_{S} / P$.

Theorem 5. Let assumptions 1-2 hold. Then

(1) $d\left(X_{S} / P\right) / d t>0$. That is, Southern catch-up raises the real value of Southern exports.

(2) $d\left(X_{S} / P\right) / d t$ is increasing in $\gamma$. That is, the faster is Southern catch-up, the greater is the growth in real Southern exports. 
Theorem 5 establishes that in theorem $2, d \bar{z} / d t$ can be replaced by $d\left(X_{S} / P\right) / d t$. That is, differences in catch-up across Southern countries can explain the figure 1 correlation between rising inequality and real export growth.

Next, we establish a result about the real value of exports. The value of Southern exports is $X_{S} \equiv Y_{N} \int_{0}^{\bar{z}} \alpha(z) d z$ and the real value of Southern exports is $X_{S} / P$.

Theorem 6. Let assumptions 1-2 hold. Then

(1) $d\left(X_{S} / P\right) / d t>0$. That is, Southern catch-up raises the real value of Southern exports.

(2) $d\left(X_{S} / P\right) / d t$ is increasing in $\gamma$. That is, the faster is Southern catch-up, the greater is the growth in real Southern exports.

Theorem 5 establishes that in theorem $2, d \bar{z} / d t$ can be replaced by $d\left(X_{S} / P\right) / d t$. That is, differences in catch-up across Southern countries can explain the figure 1 correlation between rising inequality and real export growth.

Finally, we collect a number of additional results about earnings. Recall that $h_{i}(z, t) \equiv$ $H_{i}(z, t) / L_{i}(z, t)$ and that its dependence on relative wages $w_{i}$ is suppressed. Let $\varepsilon_{i}(z, t) \equiv$ $-\partial \ln h_{i}(z, t) / \partial w_{i} \geq 0$ be the elasticity of substitution between skilled and unskilled Southern labor.

Theorem 7. Let assumptions 1-2 hold.

(1) $d\left(w_{H i} / P\right) / d t>0, i=N, S$. That is, real earnings for skilled workers rise in both the North and the South. 
(2) Assume $\rho_{N}=\rho_{S}=0$. There exist $\kappa_{S}(t) \in(0,1)$ and $\kappa_{N}(t)>0$ for which the following holds: $\varepsilon_{i}(\cdot ; t)>\kappa_{i}(t) \Rightarrow d\left(w_{L i} / P\right) / d t>0, i=N, S$. That is, if elasticities of substitution are sufficiently large then real earnings for unskilled labor rise in both the North and the South.

Part (1) is an immediate consequence of Southern productivity catch-up. Part (2) is a consequence of rising real income $Y_{i} / P$, rising inequality $w_{H i} / w_{L i}$, and the fact that $Y_{i}$ is a weighted average of $w_{H i}$ and $w_{L i}$. Part (3) is non-trivial. Rising $Y_{i} / P$ means that a weighted average of $w_{H i} / P$ and $w_{L i} / P$ is rising. With sufficiently large substitution possibilities, the wage gap between skilled and unskilled workers cannot widen too much. So even $w_{L i} / P$ must rise. This completes our discussion of welfare results.

\section{Empirics}

Our interest lies in explaining the complex evolution of Southern inequality in terms of Southern catch-up, skill-upgrading, and trade. There is one immediate problem in taking our theory to the data. The theoretical analysis takes goods $z$ as the unit of analysis. Unfortunately, internationally comparable data are only reported at the industry level. In order to bridge this gap between theory and data, in this section we augment our theoretical model by adding an industry dimension.

We know that each industry is a collection of heterogenous goods. For example, the automobile industry includes both unskilled-intensive (low-z) car seats and skill-intensive (high- $z$ ) engine blocks. It is therefore natural to think of each industry as assembling a wide range of intermediate inputs $z$ into a final good. To introduce industries, let $\mu_{j}$ be a 
measure on the unit interval that picks off the intermediate inputs used by industry $j$. Let $p(z)$ be the price of $z$ faced by producers i.e., $p(z)=P_{S}(z)$ for $z<\bar{z}$ and $p(z)=P_{N}(z)$ for $z>\bar{z}$. Let $x_{j}(p, z)$ be the amount of $z$ demanded by industry $j$. To define preferences over the $X_{j}$ rather than the intermediates $z$, re-write our Cobb-Douglas utility function as $U \equiv$ $\sum_{j} \beta_{j} \ln X_{j}$. Assuming that industry output is produced using Cobb-Douglas technologies, $\ln X_{j}=\int_{0}^{1} \alpha_{j}(z) \ln x_{j}(p, z) \mu_{j}(d z), \quad U$ becomes $U=\sum_{j} \int_{0}^{1} \beta_{j} \alpha_{j}(z) \ln x_{j}(p, z) \mu_{j}(d z)$. Since

this can be rewritten as $U=\int_{0}^{1} \alpha(z) \ln x(z) d z$, the new industry layer is consistent with the utility function used in this paper.

The only problem with introducing an industry layer, then, is that assembly potentially has implications for resource allocation. To sidestep this we assume that assembly is costless. Costless assembly introduces an indeterminacy in the location of assembly and hence in trade patterns. We break this indeterminacy by assuming that there is an arbitrarily small trade cost for the $X_{j}$ so that they are assembled and consumed in the same location. Thus, assembly will have no implications for resource allocation or trade. In short, we can seamlessly add an industry layer to the analysis.

\subsection{Skill Upgrading}

Since many of the results of this paper apply at the economy-wide level, this leaves us with only a handful of observations e.g., the 29 observations corresponding to the Southern countries of figure 1. However, our core theoretical result is a form of skill upgrading at the industry level. Specifically, let $\bar{z}_{j}$ be the competitive margin for industry $j$ i.e., all industry $j$ intermediates $z<\bar{z}_{j}$ are produced in the South. Then Southern catch-up in industry $j$ 
will raise $\bar{z}_{j}$. We can thus examine skill upgrading with the much greater sample variation obtained by pooling across countries and industries.

We measure skill upgrading as the payroll share of skilled workers. Let $h_{S j}\left(w_{S}, p, \bar{z}_{j}\right)$ be the ratio of skilled to unskilled workers in industry $j .{ }^{14}$ Then the payroll share of skilled workers may be written as

$$
P S_{j} \equiv \frac{w_{S} h_{S j}\left(w_{S}, p, \bar{z}_{j}\right)}{1+w_{S} h_{S j}\left(w_{S}, p, \bar{z}_{j}\right)}
$$

Holding $w_{S}$ constant, the direct effect of Southern catch-up is to raise $\bar{z}_{j}$. This raises $h_{S j}$ which in turn leads to skill upgrading. ${ }^{15}$ The indirect effects of Southern catch-up operate via the rise in $w_{S}$. From equation (13), there are three such effects, but these are either of a second-order of magnitude or subsumable into a regression fixed effect. ${ }^{16}$ We thus expect that the net effect of Southern catch-up in industry $j$ will be skill upgrading in industry $j$.

\subsection{The Estimating Equation}

Let $i$ denote countries and in equation (13) replace $S$ subscripts with $i$ subscripts. Also, with many countries, $\bar{z}_{j}$ requires an $i$ subscript. Let $t$ index years. Our starting point is the translog-motivated skill-upgrading regression that is the starting point of Berman et al.

\footnotetext{
${ }^{14}$ Mathematically, $h_{S j}$ is defined as

$$
h_{S j}\left(w_{S}, p, \bar{z}_{j}\right) \equiv \frac{\int_{0}^{\bar{z}_{j}} H_{S}\left(w_{S}, z\right) x_{j}(p, z) \mu_{j}(d z)}{\int_{0}^{\bar{z}_{j}} L_{S}\left(w_{S}, z\right) x_{j}(p, z) \mu_{j}(d z)}
$$

where we have re-introduced $w_{S}$ as an argument in unit demand functions $H_{S}$ and $L_{S}$.

${ }^{15}$ That $h_{S j}$ is increasing in $\bar{z}_{j}$ can be seen by calculating $\partial h_{S j} / \partial \bar{z}_{j}$ and noting that $H_{S}\left(w_{S}, \bar{z}_{j}\right) / L_{S}\left(w_{S}, \bar{z}_{j}\right)>h_{S j}\left(w_{S}, p, \bar{z}_{j}\right)$.

${ }^{16}(1)$ The rise in $w_{S}$, holding $h_{S j}$ constant, raises $P S_{j}$. (2) The rise in $w_{S}$ leads to a substitution of skilled for unskilled labor within goods. It is easy to show that this lowers $h_{S j}$ and hence lowers $P S_{j}$. (3) The rise in $w_{S}$ raises the relative price of skill-intensive intermediate inputs, thus leading to a within-industry substitutution towards less skill-intensive intermediate inputs. This lowers $h_{S j}$ and hence lowers $P S_{j}$. For a complete description of these effects, see the discussions following theorem 1.
} 
(1994), Autor et al. (1998), Feenstra and Hanson (1996a, 1997, 1999), and others:

$$
\Delta P S_{i j t}=\beta \Delta \ln \left(K_{i j t} / V_{i j t}\right)+\delta_{i}+\varepsilon_{i j t}
$$

where $K_{i j t} / V_{i j t}$ is the ratio of capital to value added in industry $j$ in country $i$ and where the $\Delta$ operator converts variables into average annual changes over the period. In most studies $i$ is taken to be the United States so that no country fixed effect is needed. In our case, we will pool across countries and introduce the country fixed effect $\delta_{i}$.

Our main focus is on the effect of $\Delta \bar{z}_{i j t}$ on $\Delta P S_{i j t}$. To this end, we proxy $\Delta \bar{z}_{i j t}$ by a measure of Southern catch-up $C_{i j t}$ that is a multi-country generalization of our equation (9) definition of Southern catch-up:

$$
C_{i j t} \equiv \Delta \pi_{i j t}-\Sigma_{n \epsilon N} \omega_{i n j} \Delta \pi_{n j t}
$$

Here, $\pi_{i j t}$ is the log of labor productivity, $n$ indexes the Northern trading partners of Southern country $i$. The Northern trading partners are taken to be the United States along with Australia, Austria, Canada, Denmark, Finland, Germany, Great Britain, Italy, and Sweden. In equation (14), $\omega_{i n j}$ is $n$ 's share of country $i$ 's trade. By trade we mean the sum of bilateral imports and exports. To isolate productivity effects from share shifts, $\omega_{i n j}$ is taken to be the average trade share over the period. We will show below that results are not sensitive to the definition of $\omega_{i n j}$.

In our baseline analysis we divide the sample into 2 periods, 1978-82 and 1984-90 and add a dummy for the 1984-90 period. This helps us avoid the debt crisis. We also consider 
growth in the endowment ratio $H_{S} / L_{S}$. This captures the fact that human capital formation is a key component of the process of catch-up. Although we have excluded human capital formation from this paper, we have fully worked out the model with it included. We review the specifics below.

To summarize, we run the regression

$$
\Delta P S_{i j t}=\beta_{1} C_{i j t}+\beta_{2} \Delta \ln \left(K_{i j t} / V_{i j t}\right)+\beta_{3} \Delta \ln \left(H_{i t} / L_{i t}\right)+\delta_{i}+\delta_{j}+\delta_{t}+\nu_{i j t}
$$

where $H_{i t} / L_{i t}$ is the endowment ratio for country $i$ in year $t$. We run weighted regressions using payroll shares as weights. More precisely, the weights are $p a y_{i j} / \sum_{j} p a y_{i j}$ where $p a y_{i j}$ is the payroll of industry $j$ in country $i$.

\subsection{Data}

Data for $\Delta P S_{i j t}$ are available from the United Nations General Industrial Statistics (GIS). The GIS reports payroll data for operative and non-operative workers. ${ }^{17}$ This distinction basically follows the U.S. distinction between production and non-production workers so that we treat operatives as unskilled workers and non-operatives as skilled workers. We calculate $P S_{i j t}$ as the payroll of non-operatives divided by total payroll. We have data on $P S_{i j t}$ for all 28 International Standard Industrial Classification (ISIC Revision 2) industries for 18 developing and newly industrialized countries over the years 1978-90. We include only those countries with GDP per capita less than 60\% of U.S. GDP per capita in 1978. Our results are not sensitive to the choice of cut-off. Ranked by GDP per capita in 1978, the 18

\footnotetext{
${ }^{17}$ We are indebted to Eli Berman for drawing our attention to these data.
} 
countries are Venezuela, Spain, Ireland, Greece, Mexico, Portugal, Uruguay, Malta, Chile, South Korea, Turkey, Peru, Columbia, Guatemala, Philippines, Egypt, India, and Ethiopia.

All data used in the definition of $C_{i j t}$ are from Antweiler and Trefler (2000). Industryspecific capital stocks $K_{i j t}$ were constructed using a 15-year double declining balance method (e.g., Leamer 1984, pages 230-34) and the UNIDO gross fixed capital formation series. The initial year used was 1963. The data were deflated using purchasing power parity-adjusted investment deflators (Summers and Heston 1992). National endowments of skilled and unskilled labor for $H_{i t} / L_{i t}$ are from the Barro and Lee (1993) database as updated by Antweiler and Trefler (2000). $H_{i t}$ is the working age population with at least 12 years of education and $L_{i t}$ is the remaining working age population.

\subsection{Results}

Estimates of equation (15) for our benchmark case are reported in column 1 of table 1 . The coefficient on Southern catch-up $C_{i j t}$ is 0.081 with a $t$-statistic of 3.75 . This supports our contention that Southern catch-up leads to skill upgrading. By implication, Southern catchup at least partly explains the complex evolution of Southern inequality. Since Southern catch-up clearly explains export growth, Southern catch-up also potentially explains the trade-inequality correlation of figure 1.

From table 1, the impact of a rising supply of skills on skill-upgrading is positive. Obviously, this is inconsistent with a movement down a demand schedule. It is consistent with the aggregate time series co-movements of factor prices and supplies in some countries (e.g., the United States), but not in others, e.g., Canada (Murphy et al. 1998) and South Korea 
(Kim and Topel 1995).

What does our model predict about this coefficient? Letting $g_{S}$ be the growth rate of the endowment ratio $H_{S} / L_{S}$, we can prove that

$$
\frac{d \bar{z}}{d\left(H_{S} / L_{S}\right)}>0 \text { and } \frac{d^{2} \bar{z}}{d t d g_{S}}>0 .
$$

From equation (16), a rise in $H_{S} / L_{S}$ leads via $\bar{z}$ to skill upgrading i.e., the coefficient on the national skill level variable is predicted to be positive. This is what we find empirically.

More conventionally, we find that capital deepening contributes to skill upgrading. Lastly, the 1984-90 time dummy is positive and large. Its value of 0.013 is comparable to the 0.010 sample mean of the dependent variable (skill upgrading $\Delta P S_{i j t}$ ). This is suggestive of accelerated technical change in the 1980s and is thus consistent with U.S. research e.g., Katz and Murphy (1992).

We have examined the sensitivity of our results to a number of alternative specifications. Column 2 of table 1 reports a specification that omits the industry fixed effects. Column 3 reports a specification that omits the growth in the supply of skilled workers. These alternative specifications do not change the key result that Southern catch-up is positively correlated with skill ugprading. There is also no change when we shrink the sample by omitting from it the OECD members (i.e., Spain, Ireland, Portugal, and Greece). Likewise, there is no change when we omit all observations with standardized residuals in excess of 2.5 .

The most important source of coefficient fragility turns out to be the choice of sample 
period. This appears in table 1 where we report results for different choices of the first period. In the table we consider the period 1978-82 (to avoid the debt crisis), 1978-83, and 1978-84. It is clear that there is some fragility, especially for the period 1978-84. Notice that the $C_{i j t}$ and $\Delta \ln \left(H_{i t} / L_{i t}\right)$ coefficients for 1978-84 move in opposite directions so that we very precisely estimate their sum. This is interesting because, from equation (16), $d^{2} \bar{z} / d t d g_{S}>0$ so that the faster is the growth of $H_{S} / L_{S}$, the greater is the impact of catch-up on skill ugprading. Thus the theory suggests that there may be some problem in separately estimating the two effects.

We divided up the sample into two periods in order to meaningfully increase the sample size. It is of some interest then that when we consider only a single period (1978-90), the coefficient does not significantly change in size, but its statistical significance falls with the fall in sample size. This is what one expects if dividing the sample into two periods and pooling is legitimate.

A key feature of the theoretical model is the interplay between Southern catch-up and trade. Since trade is central to our thinking, it is of interest to experiment with the trade weights $\omega_{i n j}$ of equation (14). To this end, let $M_{i n j t}\left(X_{i n j t}\right)$ be the value of country $i$ 's imports from (exports to) country $n$ for industry $j$ in year $t$. Let $T_{i n j t} \equiv M_{i n j t}+X_{i n j t}$ be the volume of trade between $i$ and $n$. The trade weights used in table 1 are $\omega_{i n j}=$ $\sum_{t=1978}^{1990}\left(T_{i n j t} / \sum_{n^{\prime}} T_{i n^{\prime} j t}\right) / 12$. In table 2, we consider alternative weights. In columns 1-2, $T_{i n j t}$ is replaced by $M_{i n j t}$ and $X_{i n j t}$, respectively. Thus, the estimates are not sensitive to whether imports or exports are used. In column 3, we move away from industry-specific weights to national weights by replacing $T_{i n j t}$ with its sum across industries, $\Sigma_{j} T_{i n j t}$. Again, 
the coefficient on Southern catch-up is little changed from that reported in the first column of table 1 .

In short, this rudimentary empirical exercise has presented evidence that Southern catchup (as measured by relative labor productivity growth) has a significantly positive impact on skill upgrading in 18 low- and middle-income countries. By implication, differences in catch-up among Southern countries at least partly explains the complex evolution of Southern inequality. Since catch-up obviously explains export growth, catch-up presents a possible explanation for the striking figure 1 relationship between rising inequality and export growth.

\section{Conclusion}

Among developing and newly industrialized countries, the Deininger and Squire (1996) database shows that rising inequality during the 1980s was a common occurrence. This is sharply at odds with the Stolper-Samuelson theorem which predicts that Southern inequality should have fallen. In trying to explain this complex evolution of Southern inequality, we pointed out that there is a positive correlation across Southern countries between export growth and inequality growth. This suggested to us that Southern inequality trends are linked via general equilibrium trade movements triggered by technological catch-up.

To model this, we married the Ricardian international technology differences model (Dornbusch et al. 1977) with the Heckscher-Ohlin model (Dornbusch et al. 1980). In our model, technological catch-up causes production of the least skill-intensive Northern goods to migrate South. By Southern standards, these new goods are skill intensive. Thus the 
demand for skills rises in both regions. That is, inequality rises in both the North and the South (as in Feenstra and Hanson 1996a). As importantly, Southern catch-up induces the correlation between export growth and inequality growth that we demonstrated empirically in figure 1. Further, a rudimentary empirical exercise revealed that, as predicted, Southern skill upgrading is correlated with the trade-weighted average of Southern catch-up. In short, this paper provides some initial insights into the complex evolution of Southern inequality and its relationship to changing trade patterns. 


\section{References}

Acemoglu, Daron (1998) "Why Do New Technologies Complement Skills? Directed Technical Change and Wage Inequality," Quarterly Journal of Economics, 113 (4), 10551089 .

— (2000) "Technical Change, Inequality and the Labor Market." NBER Working Paper $\# 7800$.

— , Simon Johnson, and James A. Robinson (2000) "The Colonial Origins of Comparative Development: An Empirical Investigation." NBER Working Paper \#7771.

Antweiler, Werner and Daniel Trefler (2000) "Increasing Returns and All That: A View From Trade." NBER Working Paper \#7941.

Attanasio, Orazio and Steven J. Davis (1996) "Relative Wage Movements and the Distribution of Consumption," Journal of Political Economy, 104 (6), 1227-1262.

Autor, David H., Lawrence F. Katz, and Alan B. Krueger (1998) "Computing Inequality: Have Computers Changed the Labor Market," Quarterly Journal of Economics, 113 (4), 1169-1213.

Baldwin, Robert E. and Glen G. Cain (2000) "Shifts in Relative U.S. Wages: The Role of Trade, Technology, and Factor Endowments," Review of Economics and Statistics, $82(6), 580-95$.

Barro, Robert J. and Jong-Wha Lee (1993) "International Comparisons of Educational Attainment," Journal of Monetary Economics, 32 (3), 363-94.

Berman, Eli and Stephen Machin (2000) "Skill-Biased Technology Transfer: Evidence of Factor Biased Technological Change in Developing Countries." Mimeo, Boston University.

— John Bound, and Stephen Machin (1998) "Implications of Skill-Biased Technological Change: International Evidence," Quarterly Journal of Economics, 113 (4), $1245-1279$.

— _ _ and Zvi Griliches (1994) "Changes in the Demand for Skilled Labor within U.S. Manufacturing: Evidence from the Annual Survey of Manufactures," Quarterly Journal of Economics, 109 (2), 367-397.

Bhagwati, Jagdish (1958) "Immiserizing Growth: A Geometrical Note," The Review of Economic Studies, 25, 201-205.

Borjas, George J., Richard B. Freeman, and Lawrence F. Katz (1997) "How Much Do Immigration and Trade Affect Labor Market Outcomes?," Brookings Papers on Economic Activity, (1). 
Deininger, Klaus and Lyn Squire (1996) "Measuring Income Inequality: A New Data Base," The World Bank Economic Review, 10 (3), 565-91.

Dornbusch, Rudiger, Stanley Fischer, and Paul A. Samuelson (1977) "Comparative Advantage, Trade, and Payments in a Ricardian Model with a Continuum of Goods," American Economic Review, 67 (5), 823-39.

— _ _ , and — (1980) "Heckscher-Ohlin Trade Theory with a Continuum of Goods," Quarterly Journal of Economics, 95 (2), 203-224.

Feenstra, Robert C. and Gordon H. Hanson (1996a) "Foreign Investment, Outsourcing, and Relative Wages," in Robert C. Feenstra, Gene M. Grossman, and Douglas A. Irwin, eds., The Political Economy of Trade Policy: Papers in Honor of Jagdish Bhagwati, Cambridge MA: MIT Press.

— and — (1996b) "Globalization, Outsourcing, and Wage Inequality," American Economic Review Papers and Proceedings, 86 (2), 240-245.

— and — (1997) "Foreign Direct Investment and Relative Wages: Evidence from Mexico's Maquiladoras," Journal of International Economics, 42 (3).

— and - (1999) "The Impact of Outsourcing and High-Technology Capital on Wages: Estimates for the United States, 1979-1990," Quarterly Journal of Economics, 114 (3), 907-40.

, Robert E. Lipsey, and Harry P. Bowen (1997) "World Trade Flows, 1970-1992, With Production and Tariff Data." NBER Working Paper \#5910.

Gerschenkron, Alexander (1962) Economic Backwardness in Historical Perspective, Cambridge: Belknap Press of Harvard University Press.

Goldin, Claudia and Lawrence F. Katz (1998) "The Origins of Technology-Skill Complementarity," Quarterly Journal of Economics, 113 (3), 693-732.

Hulten, Charles R. (1973) "Divisia Index Numbers," Econometrica, 41 (6), 1017-1025.

Katz, Lawrence and Kevin M. Murphy (1992) "Changes in Relative Wages, 1963-1987: Supply and Demand Factors," Quarterly Journal of Economics, 107 (1), 35-78.

Kim, Dae-Il and Robert H. Topel (1995) "Labor Markets and Economic Growth: Lessons from Korea's Industrialization, 1970-1990," in Richard B. Freeman and Lawrence F. Katz, eds., Differences and Changes in Wage Structure, Chicago and London: The University of Chicago Press.

Leamer, Edward E. (1984) Sources of International Comparative Advantage: Theory and Evidence, Cambridge, Mass: MIT Press.

Mas-Collell, Andreu, Michael D. Whinston, and Jerry R. Green (1995) Microeconomic Theory, New York: Oxford University Press. 
Murphy, Kevin M., W. Craig Riddell, and Paul M. Romer (1998) "Wages, Skills, and Technology in the United States and Canada," in Elhanan Helpman, ed., General Purpose Technologies and Economic Growth, Cambridge MA: MIT Press.

Schultz, Theodore W. (1960) "Capital Formation by Education," The Journal of Political Economy, 68 (6), 571-583.

Summers, Robert and Alan Heston (1991) "The Penn World Table (Mark 5): An Expanded Set of International Comparisons, 1950-1988," Quarterly Journal of Economics, $106(2), 327-68$.

Zhu, Susan Chun (2001) "Trade, Product Cycles and Wage Inequality: An International Perspective." Mimeo, University of Toronto. 


\section{A. Appendix}

\section{A.1. Proof of Lemma 1}

Let $L_{N}(z)$ and $H_{N}(z)$ be the amount of unskilled and skilled labor, respectively, needed to produce one unit of good $z$ in the North. Define $h_{N}(z) \equiv H_{N}(z) / L_{N}(z)$. To keep the notation clear, the relative wage $w_{N}$ has been suppressed. Since $C_{N}\left(w_{H N}, w_{L N}, z\right)$ is homogenous of degree one in $w_{H N}$ and $w_{L N}, C_{N}\left(w_{H N}, w_{L N}, z\right)=w_{L N} \cdot C_{N}\left(w_{N}, 1, z\right)$. Differentiating this with respect to $w_{L N}$ yields $\partial C_{N}\left(w_{H N}, w_{L N}, z\right) / \partial w_{L N}=C_{N}\left(w_{N}, 1, z\right)-$ $w_{N} \partial C_{N}\left(w_{N}, 1, z\right) / \partial w_{N}$. By Shepard's Lemma, we have $L_{N}(z)=\partial C_{N}\left(w_{H i}, w_{L i}, z\right) / \partial w_{L N}$. Combining the above two equations yields $\partial C_{N}\left(w_{N}, 1, z\right) / \partial w_{N}=H_{N}(z)$. Thus we have

$$
\begin{aligned}
\frac{\partial}{\partial w_{N}}\left[\frac{\partial \ln C_{N}\left(w_{H N}, w_{L N}, z\right)}{\partial z}\right] & =\frac{\partial}{\partial w_{N}}\left[\frac{\partial \ln \left[w_{L N} \cdot C_{N}\left(w_{N}, 1, z\right)\right]}{\partial z}\right]=\frac{\partial}{\partial w_{N}}\left[\frac{\partial \ln C_{N}\left(w_{N}, 1, z\right)}{\partial z}\right] \\
& =\frac{\partial}{\partial z}\left[\frac{\partial \ln C_{N}\left(w_{N}, 1, z\right)}{\partial w_{N}}\right]=\frac{\partial}{\partial z}\left[\frac{H_{N}(z)}{L_{N}(z)+w_{N} H_{N}(z)}\right] \\
& =\frac{\partial}{\partial z}\left[\frac{h_{N}(z)}{1+w_{N} h_{N}(z)}\right]=\frac{\partial h_{N}(z) / \partial z}{\left[1+w_{N} h_{N}(z)\right]^{2}}>0 .
\end{aligned}
$$

Hence, if $w_{N}<w_{S}$, then $\partial \ln C_{N}\left(w_{H N}, w_{L N}, z\right) / \partial z<\partial \ln C_{N}\left(w_{H S}, w_{L S}, z\right) / \partial z$. From inequality (1) we have $\partial \ln C_{N}\left(w_{H S}, w_{L S}, z\right) / \partial z \leq \partial \ln C_{S}\left(w_{H S}, w_{L S}, z\right) / \partial z$. Combining these two inequality yields $\partial \ln C_{N}\left(w_{H N}, w_{L N}, z\right) / \partial z<\partial \ln C_{S}\left(w_{H S}, w_{L S}, z\right) / \partial z$. This implies that inequality (2) holds.

This completes the proof of lemma 1 . Note that given factor prices, $\bar{z}$ must be unique because $C_{N}\left(w_{H N}, w_{L N}, z\right)$ and $C_{S}\left(w_{H S}, w_{L S}, z\right)$ intersect only once.

\section{A.2. Existence and Uniqueness of an Equilibrium}

Lemma 3. For $h_{N} / h_{S}$ sufficiently large, $w_{N}$ must be larger than $w_{S}$ in any equilibrium.

Proof. Plugging equation (4) into the labor market clearing condition for Southern skilled labor in equation (5) and using the zero profit condition yield

$$
H_{S}=\left(Y_{N}+Y_{S}\right) \int_{0}^{\bar{z}} \alpha(z) \frac{H_{S}(z)}{w_{H S} H_{S}(z)+w_{L S} L_{S}(z)} d z .
$$

Let $\theta_{H i}(z) \equiv w_{H S} H_{S}(z) /\left[w_{H S} H_{S}(z)+w_{L S} L_{S}(z)\right]$ be the cost share of skilled workers in region $i(=S, N)$. Multiplying equation (17) by $w_{H S}$, we have $w_{H S} H_{S}=\left(Y_{N}+Y_{S}\right) \int_{0}^{\bar{z}} \alpha(z) \theta_{H S}(z) d z$. Similarly, from the Southern unskilled labor market clearing condition we have $w_{L S} L_{S}=$ $\left(Y_{N}+Y_{S}\right) \int_{0}^{\bar{z}} \alpha(z)\left[1-\theta_{H S}(z)\right] d z$. Taking a ratio of the two yields

$$
w_{S}=\frac{1}{h_{S}} \frac{\int_{0}^{\bar{z}} \alpha(z) \theta_{H S}(z) d z}{\int_{0}^{\bar{z}} \alpha(z)\left[1-\theta_{H S}(z)\right] d z} .
$$

Using the fact that $\theta_{H S}(z)$ is increasing in $z$, equation (18) implies $w_{S}>\kappa_{S} / h_{S}$, where $\kappa_{S} \equiv$ $\theta_{H S}(0) /\left[1-\theta_{H S}(0)\right]$. Likewise, from the Northern labor market clearing conditions we have 
$w_{N}<\kappa_{N} / h_{N}$, where $\kappa_{N} \equiv\left[1-\theta_{H N}(1)\right] / \theta_{H N}(1)$. Therefore, $w_{S} / w_{N}>\left(\kappa_{S} / \kappa_{N}\right)\left(h_{N} / h_{S}\right)$.

By the regularity of production functions and the fact that endowments are strictly positive and finite so that factor prices are strictly positive and finite, $\theta_{H S}(0)$ and $\theta_{H N}(1)$ are bounded strictly away from 0 and 1 . Thus, $\kappa_{S} / \kappa_{N}$ is positive and bounded. It follows that for large enough $h_{N} / h_{S}, w_{S} / w_{N}>1$.

Lemma 4. For $h_{N} / h_{S}$ sufficiently large, there exists a unique equilibrium. Further, in the unique equilibrium $w_{N}<w_{S}$.

Proof. Equilibrium is defined as a set of prices $\left\{P_{i}(\cdot), w_{L i}, w_{H i}\right\}_{i=N, S}$ that clear product and factor markets. The following proof of the existence and uniqueness of equilibrium modifies the Dornbusch et al. (1980) proof to allow for international technology differences. In our proof we suppress $t$ as an argument of all functions.

Let $F_{i}\left(H_{i}^{0}(z), L_{i}^{0}(z)\right)$ be the production function for good $z$ in region $i(=N, S)$, where $H_{i}^{0}(z)$ and $L_{i}^{0}(z)$ are the total amounts of skilled and unskilled labor, respectively, required to produce good $z$ (as opposed to per unit demands $H_{i}(z)$ and $L_{i}(z)$ ). The social planner's problem is to choose $\left\{H_{N}^{0}(z), L_{N}^{0}(z), H_{S}^{0}(z), L_{S}^{0}(z)\right\}$ for each $z$ to maximize

$$
\int_{0}^{1} \alpha(z) \ln \left[F_{N}\left(H_{N}^{0}(z), L_{N}^{0}(z)\right)+F_{S}\left(H_{S}^{0}(z), L_{S}^{0}(z)\right)\right] d z
$$

subject to

$$
\left[\int_{0}^{1} H_{N}^{0}(z) d z, \int_{0}^{1} L_{N}^{0}(z) d z, \int_{0}^{1} H_{S}^{0}(z) d z, \int_{0}^{1} L_{S}^{0}(z) d z\right] \leq\left[H_{N}, L_{N}, H_{S}, L_{S}\right] .
$$

Let $\Phi\left(H_{N}, L_{N}, H_{S}, L_{S}\right)$ be the value of the objective function at the maximum. Let $F_{i}(z) \equiv$ $F_{i}\left(H_{i}^{0}(z), L_{i}^{0}(z)\right)$ for $i=N$, S. Let $\mu_{f}\left(f=H_{N}, L_{N}, H_{S}, L_{S}\right)$ be Langrangian multipliers, one for each inequality constraint. The Kuhn-Tucker conditions for any $L_{S}^{0}(z)$ and $H_{S}^{0}(z)$ are

$$
\begin{aligned}
\frac{\alpha(z)}{F_{N}(z)+F_{S}(z)} \cdot \frac{\partial F_{S}(z)}{\partial H_{S}^{0}(z)} & \geq \mu_{H S}, H_{S}^{0}(z) \geq 0 \text { with complementary slackness } \\
\frac{\alpha(z)}{F_{N}(z)+F_{S}(z)} \cdot \frac{\partial F_{S}(z)}{\partial L_{S}^{0}(z)} & \geq \mu_{L S}, L_{S}^{0}(z) \geq 0 \text { with complementary slackness } \\
H_{S}-\int_{0}^{1} H_{S}^{0}(z) d z & \geq 0, \mu_{H S} \geq 0 \text { with complementary slackness } \\
L_{S}-\int_{0}^{1} L_{S}^{0}(z) d z & \geq 0, \mu_{L S} \geq 0 \text { with complementary slacknes }
\end{aligned}
$$

Since the objective function is strictly quasi-concave and the constraint functions are convex, by theorem M.K.4 in Mas-Collel et al. (1995, pp.962), a solution to the above Kuhn-Tucker conditions exists and is unique. We next show that the competitive equilibrium solution satisfies the above Kuhn-Tucker conditions.

By lemma 1, when $w_{N}<w_{S}$, the South specializes in goods $z \in[0, \bar{z}]$ and the North specializes in goods $z \in[\bar{z}, 1]$ where $\bar{z}$ satisfies $P_{N}(\bar{z})=P_{S}(\bar{z})$. Equations $(21)-(22)$ are 
trivially satisfied. For $z>\bar{z}, H_{S}^{0}(z)=L_{S}^{0}(z)=0$ and equations (19)-(20) hold. So consider equations $(19)-(20)$ for $z<\bar{z}$. Start with equation (20). In our competitive equilibrium, $\partial F_{S}(z) / \partial L_{S}^{0}(z)=w_{L S} / P_{S}(z), F_{N}(z)+F_{S}(z)=F_{S}(z)$ and (by equation 4) $F_{S}(z)=\alpha(z)\left(Y_{N}+Y_{S}\right) / P_{S}(z)$ so that the left hand side of equation (20) is

$$
\frac{\alpha(z)}{F_{N}(z)+F_{S}(z)} \cdot \frac{\partial F_{S}(z)}{\partial L_{S}^{0}(z)}=\frac{P_{S}(z)}{Y_{N}+Y_{S}} \cdot \frac{\partial F_{S}(z)}{\partial L_{S}^{0}(z)}=\frac{w_{L S}}{Y_{N}+Y_{S}} .
$$

We are allowed one normalization. We choose $w_{L S} /\left(Y_{N}+Y_{S}\right)=\mu_{L S}$. Then equation (23) implies equation (20).

To show that our competitive equilibrium solution satisfies equation (19), derive the $H_{S}^{0}(z)$ equivalent of equation $(23)$ :

$$
\frac{\alpha(z)}{F_{N}(z)+F_{S}(z)} \cdot \frac{\partial F_{S}(z)}{\partial H_{S}^{0}(z)}=\frac{w_{H S}}{Y_{N}+Y_{S}} .
$$

Hence equation (19) is satisfied if $w_{H S} /\left(Y_{N}+Y_{S}\right)=\mu_{H S}$. (We cannot use another normalization to establish this.) Dividing equation (19) by equation (20) yields $\mu_{H S}=\mu_{L S} \frac{\partial F_{S}(z)}{\partial H_{S}^{0}(z)} / \frac{\partial F_{S}(z)}{\partial L_{S}^{0}(z)}=$ $\frac{w_{L S}}{Y_{N}+Y_{S}} \cdot \frac{w_{H S} / P_{S}(z)}{w_{H S} / P_{S}(z)}$. Thus, our competitive equilibrium values satisfy equations (19)-(22).

For the Northern version of equations $(19)-(22)$, the only additional step comes from not being able to normalize (i.e., $w_{L S} /\left(Y_{N}+Y_{S}\right)=\mu_{L S}$. $)$ To get around this, establish equation (23) with $z=\bar{z}$ and $S=N$ to obtain $w_{L N} /\left(Y_{N}+Y_{S}\right)=\mu_{L N}$.

\section{A.3. Downward Sloping Aggregate Relative Demands}

Lemma 5. Given $\bar{z}, \partial N(\bar{z}) / \partial w_{N}<0$ and $\partial S(\bar{z}) / \partial w_{S}<0$. That is, the aggregate demand for skilled labor relative to unskilled labor is downward sloping.

Proof. We only consider the Southern labor market. Let $\varepsilon_{S}(z) \equiv-\partial \ln h_{S}(z, t) / \partial w_{S}>0$ be the elasticity of substitution between skilled and unskilled workers for Southern good $z$. Let $\theta_{H S}(z)$ and $\theta_{L S}(z)$ be the cost shares of skilled and unskilled workers, respectively. Define $Y_{H S} \equiv w_{H S} H_{S} / Y_{S}$, and $Y_{L S} \equiv w_{L S} L_{S} / Y_{S}$. Then given $\bar{z}$,

$$
\frac{\partial S(\bar{z})}{\partial w_{S}}=-\frac{1}{w_{S} Y_{H S}} \int_{0}^{\bar{z}} \alpha(z) \theta_{H S}(z)\left\{\theta_{L S}(z)\left[\varepsilon_{S}(z)-1\right]+Y_{L S}\right\} d z .
$$

By inspection, if $\partial S(\bar{z}) / \partial w_{S}<0$ for $\varepsilon_{S}(\cdot)=0$, then $\partial S(\bar{z}) / \partial w_{S}<0$ for all $\varepsilon_{S}(\cdot) \geq 0$. We therefore only consider the case where $\varepsilon_{S}(\cdot)=0$. Then

$$
\frac{d S(\bar{z})}{d w_{S}}=\frac{1}{w_{S} Y_{H S}} \int_{0}^{\bar{z}} \alpha(z)\left[\theta_{L S}(z)-Y_{L S}\right] \theta_{H S}(z) d z .
$$

Since $\int_{0}^{\bar{z}} \alpha(z)\left[\theta_{L S}(z)-Y_{L S}\right] d z=0,{ }^{18}$ and $\theta_{L S}(z)-Y_{L S}$ decreases in $z$, there exists a $z^{0} \in(0, \bar{z})$ such that (i) when $z=z^{0}, \theta_{L S}(z)-Y_{L S}=0$; (ii) when $z<z^{0}, \theta_{L S}(z)-Y_{L S}>0$; (iii) when

\footnotetext{
${ }^{18}$ Multiplying equation (17) by $w_{H S}$ implies $w_{H S} H_{S} /\left(Y_{N}+Y_{S}\right)=\int_{0}^{\bar{z}} \alpha(z) \theta_{H S}(z) d z$. The balance-of-trade
} 
$z>z^{0}, \theta_{L S}(z)-Y_{L S}<0$. Further, since $\theta_{H S}(z)$ increases in $z$, we have (i) when $z \leq z^{0}$, $\theta_{H S}(z) \leq \theta_{H S}\left(z^{0}\right)$ and (ii) when $z>z^{0}, \theta_{H S}(z)>\theta_{H S}\left(z^{0}\right)$. Therefore, equation (24) implies

$$
\begin{aligned}
\frac{d S(\bar{z})}{d w_{S}} & <\frac{1}{w_{S} Y_{H S}}\left[\int_{0}^{z^{0}} \alpha(z)\left[\theta_{L S}(z)-Y_{L S}\right] \theta_{H S}\left(z^{0}\right) d z+\int_{z^{0}}^{\bar{z}} \alpha(z)\left[\theta_{L S}(z)-Y_{L S}\right] \theta_{H S}\left(z^{0}\right) d z\right] \\
& =\frac{\theta_{H S}\left(z^{0}\right)}{w_{S} Y_{H S}} \int_{0}^{\bar{z}} \alpha(z)\left[\theta_{L S}(z)-Y_{L S}\right] d z=0
\end{aligned}
$$

as required.

\section{A.4. Proofs of the Core Theorems 1-3}

The following proofs are based on differential equation system (25), which is derived by totally differentiates equilibrium conditions (6)-(8).

$$
\left[c_{j k}\right]\left[\begin{array}{l}
d \bar{z} / d t \\
d w_{S} / d t \\
d w_{N} / d t
\end{array}\right]=\left[b_{j}\right], \text { where }\left[c_{j k}\right]=\left[\begin{array}{lll}
B_{\bar{z}} & B_{w_{S}} & B_{w_{N}} \\
S_{\bar{z}} & S_{w_{S}} & 0 \\
N_{\bar{z}} & 0 & N_{w_{N}}
\end{array}\right] \text { and }\left[b_{j}\right]=\left[\begin{array}{l}
-B_{t} \\
-S_{t} \\
-N_{t}
\end{array}\right]
$$

Note that subscripts on $B, S$, and $N$ denote partial derivations e.g., $B_{\bar{z}} \equiv \partial B / \partial \bar{z}$.

The elements of $\left[c_{j k}\right]$ and $\left[b_{j}\right]$ are as followings. Note that all variables except $\alpha(\cdot)$ depend

condition implies $\left(Y_{N}+Y_{S}\right) / Y_{S}=1 / \int_{0}^{\bar{z}} \alpha(z) d z$. Therefore,

$$
Y_{H S}=\frac{w_{H S} H_{S}}{Y_{S}}=\frac{w_{H S} H_{S}}{Y_{N}+Y_{S}} \frac{Y_{N}+Y_{S}}{Y_{S}}=\frac{\int_{0}^{\bar{z}} \alpha(z) \theta_{H S}(z) d z}{\int_{0}^{\bar{z}} \alpha(z) d z}
$$

Likewise, $Y_{L S} \int_{0}^{\bar{z}} \alpha(z) d z=\int_{0}^{\bar{z}} \alpha(z) \theta_{L S}(z) d z$. 
on the technology state $t$. To simplify notion, $t$ is suppressed unless it is necessary.

$$
\begin{aligned}
c_{11} & =\frac{\alpha(\bar{z})}{\int_{0}^{\bar{z}} \alpha(z) d z \int_{\bar{z}}^{1} \alpha(z) d z}-\frac{\partial}{\partial \bar{z}} \ln \left[\frac{C_{N}\left(w_{H N}, w_{L N}, \bar{z}, t\right)}{C_{S}\left(w_{H S}, w_{L S}, \bar{z}, t\right)}\right]>0 \\
c_{12} & =\frac{1}{w_{S}}\left[\theta_{H S}(\bar{z})-Y_{H S}\right]>0 c_{13}=\frac{1}{w_{N}}\left[Y_{H N}-\theta_{H N}(\bar{z})\right]>0 \\
c_{21} & =\alpha(\bar{z}) \frac{\theta_{H S}(\bar{z})-Y_{H S}}{Y_{H S}}>0 \\
c_{22} & =-\frac{1}{w_{S} Y_{H S}} \int_{0}^{\bar{z}} \alpha(z) \theta_{H S}(z)\left[\theta_{L S}(z)\left(\varepsilon_{S}(z)-1\right)+Y_{L S}\right] d z<0 c_{23}=0 \\
c_{31} & =\alpha(\bar{z}) \frac{Y_{H N}-\theta_{H N}(\bar{z})}{Y_{H N}}>0 c_{32}=0 \\
c_{33} & =-\frac{1}{w_{N} Y_{H N}} \int_{\bar{z}}^{1} \alpha(z) \theta_{H N}(z)\left[\theta_{L N}(z)\left(\varepsilon_{N}(z)-1\right)+Y_{L N}\right] d z<0 \\
b_{1} & \equiv \gamma \\
b_{2} & =-\frac{1}{Y_{H S}} \int_{0}^{\bar{z}}\left[\frac{\partial \ln h_{S}(z, t)}{d t}\right] \alpha(z) \theta_{L S}(z) \theta_{H S}(z) d z \\
b_{3} & =-\frac{1}{Y_{H N}} \int_{\bar{z}}^{1}\left[\frac{\partial \ln h_{N}(z, t)}{d t}\right] \alpha(z) \theta_{L N}(z) \theta_{H N}(z) d z
\end{aligned}
$$

where $\theta_{L i}(z) \equiv w_{L i} L_{i}(z, t) /\left[w_{L i} L_{i}(z, t)+w_{H i} H_{i}(z, t)\right], \theta_{H i}(z)=1-\theta_{L i}(z), Y_{L i} \equiv w_{L i} L_{i} /\left(w_{L i} L_{i}+\right.$ $\left.w_{H i} H_{i}\right), Y_{H i}=1-Y_{L i}, \varepsilon_{i}(z) \equiv-\partial \ln h_{i}(z, t) / \partial \ln w_{i}$.

$c_{11}$ is positive because the North has a comparative advantage in more skill-intensive goods (lemma 1.) By lemma $5, c_{22} \equiv \partial S(\bar{z}) / \partial w_{S}$ and $c_{33} \equiv \partial N(\bar{z}) / \partial w_{N}$ are negative. The signs of other elements in $\left[c_{j k}\right]$ follow from the convention that a higher $z$ good uses relatively more skilled labor. Finally, the signs of the $c_{j k}$ imply that the determinant $\left|c_{j k}\right|$ is strictly positive.

Using the fact that $\left|c_{j k}\right|>0$, one can invert equation (25) to yield equation (10) with

$$
\begin{aligned}
\frac{d \bar{z}}{d t} & =\left(c_{22} c_{33} \gamma-c_{12} c_{33} b_{2}-c_{22} c_{13} b_{3}\right)\left|c_{j k}\right|^{-1} \\
\frac{d w_{S}}{d t} & =\left[-c_{21} c_{33} \gamma+\left(c_{11} c_{33}-c_{13} c_{31}\right) b_{2}+c_{21} c_{13} b_{3}\right]\left|c_{j k}\right|^{-1} \\
\frac{d w_{N}}{d t} & =\left[-c_{31} c_{22} \gamma+c_{12} c_{31} b_{2}+\left(c_{11} c_{22}-c_{21} c_{12}\right) b_{3}\right]\left|c_{j k}\right|^{-1} .
\end{aligned}
$$

\section{Proof of theorem 1}

With neutral technical change, $b_{2}=b_{3}=0$. Equations (28)-(30) thus imply that $d \bar{z} / d t$, $d w_{N} / d t$ and $d w_{S} / d t$ have the same signs as $\gamma$. The theorem follows immediately.

\section{Proof of theorem 2}

The theorem follows from the fact that the three coefficients on $\gamma$ equations (28)-(30) are positive.

\section{Proof of lemma 2}


Define $b_{2}^{\prime} \equiv \int_{0}^{\bar{z}} \alpha(z) \theta_{L S}(z) \theta_{H S}(z) d z / Y_{H S}>0$, and $b_{3}^{\prime} \equiv \int_{\bar{z}}^{1} \alpha(z) \theta_{L N}(z) \theta_{H N}(z) d z / Y_{H N}>$ 0 . Under assumption $1, b_{2}=-\rho_{S} b_{2}^{\prime}$, and $b_{3}=-\rho_{N} b_{3}^{\prime}$. Substituting these expressions for $b_{2}$ and $b_{3}$ into equations (28)-(30) yields equation (10) with

(1) $a_{w_{S}}=a_{\bar{z}}=-c_{13} b_{3}^{\prime} / c_{33}>0$ and $a_{w_{N}}=-\left(c_{11} c_{22}-c_{12} c_{21}\right) b_{3}^{\prime} / c_{22} c_{31}<0$,

(2) $b_{w_{N}}=b_{\bar{z}}=-c_{12} b_{2}^{\prime} / c_{22}>0$ and $b_{w_{S}}=-\left(c_{11} c_{33}-c_{13} c_{31}\right) b_{2}^{\prime} / c_{21} c_{33}<0$,

(3) $c_{w_{N}}=-c_{22} c_{31} /\left|c_{j k}\right|>0, c_{w_{S}}=-c_{21} c_{33} /\left|c_{j k}\right|>0$ and $c_{\bar{z}}=c_{22} c_{33} /\left|c_{j k}\right|>0$.

\section{Proof of theorem 3}

This follows immediately from equation (10) and lemma 2.

\section{A.5. Proof of theorem 4}

(1) $P$ is the Cobb-Douglas price index implicitly defined by $\ln P(t) \equiv \int_{0}^{\bar{z}} \alpha(z)$

$\ln P_{S}(z, t) d z+\int_{\bar{z}}^{1} \alpha(z) \ln P_{N}(z, t) d z$. Differentiating $P(t)$ and using equation (4) yields $d \ln P(t) / d t=\int_{0}^{\bar{z}} \alpha(z)\left[d \ln P_{S}(z, t) / d t\right] d z+\int_{\bar{z}}^{1} \alpha(z)\left[d \ln P_{N}(z, t) / d t\right] d z$. Differentiating the zero-profit condition $P_{i}(z, t)=w_{H i} H_{i}(z, t)+w_{L i} L_{i}(z, t)$,

$$
\frac{d \ln P_{i}(z, t)}{d t}=\frac{\partial \ln P_{i}(z, t)}{\partial t}+\left[\theta_{H S}(z) \frac{d \ln w_{H S}}{d t}+\theta_{L S}(z) \frac{d \ln w_{L S}}{d t}\right] .
$$

The first term in $d \ln P_{i}(z, t) / d t$ reflects the impact of technical change on product prices for given wages. The second term reflects the impact of change in wages on product prices for given technology levels. Denote $\pi_{i}(z, t) \equiv-\partial \ln P_{i}(z, t) / \partial t=-\partial \ln C_{i}\left(w_{H i}, w_{L i}, z, t\right) / \partial t$ $(i=N, S)$. Recall that in section 3 , we assumed that the $C_{i}\left(w_{H i}, w_{L i}, z, t\right)$ are non-increasing in $t$, i.e., $\pi_{i}(z, t) \geq 0$. In the following, $t$ will be dropped as an argument. Thus, the change in the price index can be written as

$$
\begin{aligned}
\frac{d \ln P}{d t}= & \int_{0}^{\bar{z}} \alpha(z)\left[-\pi_{S}(z)+\theta_{H S}(z) \frac{d \ln w_{H S}}{d t}+\theta_{L S}(z) \frac{d \ln w_{L S}}{d t}\right] d z \\
& +\int_{\bar{z}}^{1} \alpha(z)\left[-\pi_{N}(z)+\theta_{H N}(z) \frac{d \ln w_{H N}}{d t}+\theta_{L N}(z) \frac{d \ln w_{L N}}{d t}\right] d z .
\end{aligned}
$$

As derived in footnote 18, $Y_{H S}=\int_{0}^{\bar{z}} \alpha(z) \theta_{H S}(z) d z / \int_{0}^{\bar{z}} \alpha(z) d z$ and $Y_{L S}=\int_{0}^{\bar{z}} \alpha(z) \theta_{L S}(z) d z /$ $\int_{0}^{\bar{z}} \alpha(z) d z$. Thus $\int_{0}^{\bar{z}} \alpha(z)\left[\theta_{H S}(z) \frac{d \ln w_{H S}}{d t}+\theta_{L S}(z) \frac{d \ln w_{L S}}{d t}\right] d z=\int_{0}^{\bar{z}} \alpha(z)\left[Y_{H S} \frac{d \ln w_{H S}}{d t}+Y_{L S} \frac{d \ln w_{L S}}{d t}\right] d z$ $=\int_{0}^{\bar{z}} \alpha(z) \frac{d \ln Y_{S}}{d t} d z$. Plugging this and a similar Southern equation into equation (31) yields $\frac{d \ln P}{d t}=-\left[\int_{0}^{\bar{z}} \alpha(z) \pi_{S}(z) d z+\int_{\bar{z}}^{1} \alpha(z) \pi_{N}(z) d z\right]+\frac{d \ln Y_{N}}{d t} \int_{\bar{z}}^{1} \alpha(z) d z+\frac{d \ln Y_{S}}{d t} \int_{0}^{\bar{z}} \alpha(z) d z$. 
From equation (32), the change in Southern real national income can be written as

$$
\frac{d \ln \left(Y_{S} / P\right)}{d t}=\int_{0}^{\bar{z}} \alpha(z) \pi_{S}(z) d z+\int_{\bar{z}}^{1} \alpha(z) \pi_{N}(z) d z+\frac{d \ln \left(Y_{S} / Y_{N}\right)}{d t} \int_{\bar{z}}^{1} \alpha(z) d z .
$$

By convention, the $\pi_{i}(\cdot)$ are non-negative. By the balanced trade condition, $d \ln \left(Y_{S} / Y_{N}\right) / d t=$ $\left[\alpha(\bar{z}) /\left(\int_{0}^{\bar{z}} \alpha(z) d z \int_{\bar{z}}^{1} \alpha(z) d z\right)\right] d \bar{z} / d t$ which is strictly positive by assumption $2(d \bar{z} / d t>0)$. Hence each term in $d \ln \left(Y_{S} / P\right) / d t$ is positive and one term is strictly positive.

From equation (32), change in Northern real national income can be written as

$$
\frac{d \ln \left(Y_{N} / P\right)}{d t}=\int_{0}^{\bar{z}} \alpha(z) \pi_{S}(z) d z+\int_{\bar{z}}^{1} \alpha(z) \pi_{N}(z) d z-\frac{d \ln \left(Y_{S} / Y_{N}\right)}{d t} \int_{0}^{\bar{z}} \alpha(z) d z .
$$

The following will show that $\int_{0}^{\bar{z}} \alpha(z) \pi_{S}(z) d z>d \ln \left(Y_{S} / Y_{N}\right) / d t \cdot \int_{0}^{\bar{z}} \alpha(z) d z$. Combining this with the assumption that $\pi_{N}(\cdot)$ is non-negative implies $d \ln \left(Y_{N} / P\right) / d t>0$.

Under part (3) of assumption $2, \gamma_{H} \equiv \partial \ln \left[H_{N}(z, t) / H_{S}(z, t)\right] / \partial t$ is independent of $z$. We can therefore re-write the $\pi_{i}(\cdot)$ as $\pi_{N}(z)=\rho_{N} \theta_{L N}(z)-\partial \ln H_{N}(z, t) / \partial t$ and $\pi_{S}(z)=$ $\rho_{S} \theta_{L S}(z)+\gamma_{H}-\partial \ln H_{N}(z, t) / \partial t$. These $\pi_{i}(\cdot)$, the expression for $d \ln \left(Y_{S} / Y_{N}\right) / d t$ above, and the equation (28) expression for $d \bar{z} / d t$ can be substituted into equation (33) to yield

$$
\begin{aligned}
\frac{d \ln \left(Y_{N} / P\right)}{d t}= & \int_{0}^{\bar{z}} \alpha(z)\left[\rho_{S} \theta_{L S}(z)+\gamma_{H}-\frac{\partial \ln H_{N}(z, t)}{\partial t}\right] d z+\int_{\bar{z}}^{1} \alpha(z)\left[\rho_{N} \theta_{L N}(z)-\right. \\
& \left.\frac{\partial \ln H_{N}(z, t)}{\partial t}\right] d z-\frac{\alpha(\bar{z})}{\int_{0}^{\bar{z}} \alpha(z) \int_{\bar{z}}^{1} \alpha(z) d z} \frac{\left[c_{22} c_{33} \gamma-c_{12} c_{33} b_{2}-c_{22} c_{13} b_{3}\right]}{\left|c_{j k}\right|} \cdot \int_{0}^{\bar{z}} \alpha(z) .
\end{aligned}
$$

From lemma 1 and the expression for $c_{11}$ below equation $(25), \alpha(\bar{z}) /\left[\int_{0}^{\bar{z}} \alpha(z) \int_{\bar{z}}^{1} \alpha(z) d z\right]<$ $c_{11}$. Combining this result together with part (3) of assumption $2\left(\partial \ln H_{N}(z, t) / \partial t\right.$ is nonpositive), part (1) of assumption $2\left(b_{2} \leq 0\right.$ and $\left.b_{3} \leq 0\right)$ and the fact that $\gamma>\gamma_{H}+\rho_{S} \theta_{L S}(\bar{z})$, we can toss out positive terms to obtain

$$
\frac{d \ln \left(Y_{N} / P\right)}{d t}>\gamma_{H} \int_{0}^{\bar{z}} \alpha(z) d z+\int_{0}^{\bar{z}} \alpha(z) \rho_{S} \theta_{L S}(z) d z-\frac{c_{11} c_{22} c_{33}}{\left|c_{j k}\right|}\left[\gamma_{H}+\rho_{S} \theta_{L S}(\bar{z})\right] \cdot \int_{0}^{\bar{z}} \alpha(z) .
$$

Since $c_{11} c_{22} c_{33}<\left|c_{j k}\right|$ and $\theta_{L S}(z)>\theta_{L S}(\bar{z})$ for all $z<\bar{z}, d \ln \left(Y_{N} / P\right)>0$ follows. Note that this result holds without part (2) of assumption 2 .

(2) We compare the price of any Southern good $z$ with that of any Northern good $z^{\prime}$. Since in equilibrium $P_{S}(\bar{z}, t)=P_{N}(\bar{z}, t)$ always holds, the change in the relative price can be written as

$$
\frac{d}{d t} \ln \frac{P_{N}\left(z^{\prime}, t\right)}{P_{S}(z, t)}=\frac{d}{d t} \ln \frac{P_{N}\left(z^{\prime}, t\right)}{P_{N}(\bar{z}, t)}+\frac{d}{d t} \ln \frac{P_{S}(\bar{z}, t)}{P_{S}(z, t)} .
$$

In the following we separately sign the derivatives $d \ln \left[P_{N}\left(z^{\prime}, t\right) / P_{N}(\bar{z}, t)\right] / d t$ and $d \ln \left[P_{S}(\bar{z}, t) / P_{S}\left(z^{\prime}, t\right)\right] / d t$. 
Under assumption 1 , the change in $P_{S}(z, t)$ is equal to

$$
\frac{d \ln P_{S}(z, t)}{d t}=\left[\frac{d \ln w_{H S}}{d t}-\theta_{L S}(z) \frac{d \ln w_{S}}{d t}\right]+\left[\frac{\partial \ln H_{S}(z, t)}{\partial t}-\theta_{L S}(z) \rho_{S}\right] .
$$

Thus,

$$
\frac{d}{d t} \ln \frac{P_{S}(\bar{z}, t)}{P_{S}(z, t)}=\left[\theta_{L S}(z)-\theta_{L S}(\bar{z})\right]\left(\frac{d \ln w_{S}}{d t}+\rho_{S}\right)+\frac{\partial}{\partial t} \ln \frac{H_{S}(\bar{z}, t)}{H_{S}(z, t)}+\frac{\partial \ln P_{S}(\bar{z}, t)}{\partial \bar{z}} \frac{d \bar{z}}{d t} .
$$

Part (3) of assumption 2 implies $\partial \ln \left[H_{S}(\bar{z}, t) / H_{S}(z, t)\right] / \partial t=0$. Likewise, the change in the relative price $P_{N}\left(z^{\prime}, t\right) / P_{N}(\bar{z}, t)$ can be written as

$$
\frac{d}{d t} \ln \frac{P_{N}\left(z^{\prime}, t\right)}{P_{N}(\bar{z}, t)}=\left[\theta_{L N}(\bar{z})-\theta_{L N}\left(z^{\prime}\right)\right]\left(\frac{d \ln w_{N}}{d t}+\rho_{N}\right)-\frac{d \ln P_{N}(\bar{z}, t)}{d \bar{z}} \frac{d \bar{z}}{d t} .
$$

Therefore,

$$
\begin{aligned}
\frac{d}{d t} \ln \frac{P_{N}\left(z^{\prime}, t\right)}{P_{S}(z, t)}= & {\left[\theta_{L N}(\bar{z})-\theta_{L N}\left(z^{\prime}\right)\right]\left(\frac{d \ln w_{N}}{d t}+\rho_{N}\right)+\left[\theta_{L S}(z)-\theta_{L S}(\bar{z})\right]\left(\frac{d \ln w_{S}}{d t}+\rho_{S}\right) } \\
& -\frac{d \ln \left[P_{N}(\bar{z}, t) / P_{S}(\bar{z}, t)\right]}{d \bar{z}} \frac{d \bar{z}}{d t} .
\end{aligned}
$$

With zero profits, lemma 1 implies $d \ln \left[P_{N}(\bar{z}, t) / P_{S}(\bar{z}, t)\right] / d \bar{z}<0$. Parts (1)-(2) of assumption 2, together with the fact that $\theta_{L N}(\bar{z})>\theta_{L N}\left(z^{\prime}\right)$ and $\theta_{L S}(z)>\theta_{L S}(\bar{z})$, imply $d \ln \left[P_{N}\left(z^{\prime}, t\right) / P_{S}(z, t)\right] / d t>0$.

(3) Differentiating the trade balance condition yields $d \ln \left(Y_{S} / Y_{N}\right) / d t=[\alpha(\bar{z}) /$

$\left.\left(\int_{0}^{\bar{z}} \alpha(z) d z \int_{\bar{z}}^{1} \alpha(z) d z\right)\right] d \bar{z} / d t$, which implies that $d \ln \left(Y_{S} / Y_{N}\right) / d t$ has the same sign as $d \bar{z} / d t$. The proof follows from part (2) of assumption 2 .

\section{Proof of theorem 5}

(1) The volume of Southern exports is $X_{S}=\int_{0}^{\bar{z}} \alpha(z) d z Y_{N}$. So growth in Southern real exports is equal to

$$
\frac{d \ln \left(X_{S} / P\right)}{d t}=\frac{\alpha(\bar{z})}{\int_{0}^{\bar{z}} \alpha(z) d z} \frac{d \bar{z}}{d t}+\frac{d \ln \left(Y_{N} / P\right)}{d t} .
$$

By assumption 2 and theorem $4, d \ln \left(X_{S} / P\right) / d t>0$.

(2) By theorem 2, $d \bar{z} / d t$ increases in $\gamma$. Now we need to prove that $d \ln \left(Y_{N} / P\right) / d t$ increases in $\gamma$ as well. Combining equations (11) and (34) yields

$$
\begin{aligned}
\frac{d \ln \left(Y_{N} / P\right)}{d t}= & \int_{0}^{\bar{z}} \alpha(z)\left[\gamma+\rho_{S}\left(\theta_{L S}(z)-\theta_{L S}(\bar{z})\right)+\rho_{N} \theta_{L N}(\bar{z})-\frac{\partial \ln H_{N}(z, t)}{\partial t}\right] d z \\
& +\int_{\bar{z}}^{1} \alpha(z)\left[\rho_{N} \theta_{L N}(z)-\frac{\partial \ln H_{N}(z, t)}{\partial t}\right] d z \\
& -\left[c_{11}+\frac{\partial}{\partial \bar{z}} \ln \frac{C_{N}\left(w_{H N}, w_{L N}, \bar{z}, t\right)}{C_{S}\left(w_{H S}, w_{L S}, \bar{z}, t\right)}\right] \frac{c_{22} c_{33} \gamma-c_{12} c_{33} b_{2}-c_{22} c_{13} b_{3}}{\left|c_{j k}\right|} \cdot \int_{0}^{\bar{z}} \alpha(z)
\end{aligned}
$$


Thus,

$$
\frac{d^{2} \ln \left(Y_{N} / P\right)}{d t d \gamma}=\left[1-\frac{c_{11} c_{22} c_{33}}{\left|c_{j k}\right|}\right] \int_{0}^{\bar{z}} \alpha(z) d z
$$

Since $c_{11} c_{22} c_{33}<\left|c_{j k}\right|, d^{2} \ln \left(Y_{N} / P\right) / d t d \gamma>0$.

\section{A.6. Proof of theorem 7}

(1) Using $\int_{0}^{1} \alpha(z) \equiv 1, d \ln P / d t$ in equation (32) can be rewritten as

$$
\frac{d \ln P}{d t}=-\left[\int_{0}^{\bar{z}} \alpha(z) \pi_{S}(z, t) d z+\int_{\bar{z}}^{1} \alpha(z) \pi_{N}(z, t) d z\right]+\frac{d \ln Y_{S}}{d t}-\frac{d \ln \left(Y_{S} / Y_{N}\right)}{d t} \int_{\bar{z}}^{1} \alpha(z) d z
$$

Differentiating the trade balance condition yields $d \ln \left(Y_{S} / Y_{N}\right) / d t=\left[\alpha(\bar{z}) /\left(\int_{0}^{\bar{z}} \alpha(z) d z \int_{\bar{z}}^{1} \alpha(z) d z\right)\right]$ $d \bar{z} / d t$. The change in Southern national income can be rewritten as $d \ln Y_{S} / d t=Y_{H S} d \ln w_{S} / d t+$ $d \ln w_{L S} / d t$. The assumption $\rho_{S}=\rho_{N}=0$ implies that $b_{2}=b_{3}=0, \pi_{N}(z)=-\partial \ln H_{N}(z, t) / \partial t$ and $\pi_{S}(z)=\gamma-\partial \ln H_{N}(z, t) / \partial t$. Plugging these into equation (36) yields

$$
\frac{d \ln P}{d t}=-\left[\gamma \int_{0}^{\bar{z}} \alpha(z) d z-\frac{\partial \ln H_{N}(z, t)}{\partial t}\right]+\left[Y_{H S} \frac{d \ln w_{S}}{d t}+\frac{d \ln w_{L S}}{d t}\right]-\frac{\alpha(\bar{z})}{\int_{0}^{\bar{z}} \alpha(z) d z} \frac{d \bar{z}}{d t}
$$

Using this and equation (29), the change in the real wage of Southern unskilled labor is

$$
\frac{d \ln \left(w_{L S} / P\right)}{d t}=\left[\gamma \int_{0}^{\bar{z}} \alpha(z) d z-\frac{\partial \ln H_{N}(z, t)}{\partial t}\right]+\frac{Y_{H S}}{w_{S}} \frac{c_{21} c_{33} \gamma}{\left|c_{j k}\right|}+\frac{\alpha(\bar{z})}{\int_{0}^{\bar{z}} \alpha(z) d z} \frac{c_{22} c_{33} \gamma}{\left|c_{j k}\right|} .
$$

Using $\left|c_{j k}\right|<c_{11} c_{22} c_{33}$ and part (3) of assumption 2 that $\partial \ln H_{N}(z, t) / \partial t$ is non-positive, we have

$$
\begin{aligned}
\frac{d \ln \left(w_{L S} / P\right)}{d t} \cdot\left|c_{j k}\right| & >\gamma \cdot c_{33}\left[c_{11} c_{22} \int_{0}^{\bar{z}} \alpha(z) d z+\frac{Y_{H S}}{w_{S}} \cdot c_{21}+\frac{\alpha(\bar{z})}{\int_{0}^{\bar{z}} \alpha(z) d z} \cdot c_{22}\right] \\
& >\gamma \cdot c_{33}\left[\frac{\alpha(\bar{z})}{\int_{0}^{\bar{z}} \alpha(z) d z \int_{\bar{z}}^{1} \alpha(z) d z} c_{22}+\frac{Y_{H S}}{w_{S}} \cdot c_{21}\right] .
\end{aligned}
$$

When $\varepsilon_{S}(\cdot)=1, c_{22}=\left(Y_{L S} / w_{S}\right) \int_{0}^{\bar{z}} \alpha(z) d z$. Plugging $c_{21}$ and $c_{22}$ into equation (37) yields

$$
\frac{d \ln \left(w_{L S} / P\right)}{d t} \cdot\left|c_{j k}\right|>-\gamma \cdot c_{33}\left\{\frac{\alpha(\bar{z})\left[Y_{L S} \int_{0}^{\bar{z}} \alpha(z) d z+\theta_{L S}(\bar{z}) \int_{\bar{z}}^{1} \alpha(z) d z\right]}{w_{S} \int_{\bar{z}}^{1} \alpha(z) d z}\right\}>0
$$

It is easy to see that when $\varepsilon_{S}(\cdot) \geq 1, d \ln \left(w_{L S} / P\right) / d t>0$ still holds.

(2) Similar to the derivation in part (2), the change in the real wage of Northern unskilled 
labor can be written as

$$
\frac{d \ln \left(w_{L N} / P\right)}{d t}=\left[\gamma \int_{0}^{\bar{z}} \alpha(z) d z-\frac{\partial \ln H_{N}(z, t)}{\partial t}\right]-\frac{\alpha(\bar{z})}{\int_{\bar{z}}^{1} \alpha(z) d z} \frac{c_{22} c_{33} \gamma}{\left|c_{j k}\right|}+\frac{Y_{H N}}{w_{N}} \frac{c_{31} c_{22} \gamma}{\left|c_{j k}\right|} .
$$

Then

$$
\begin{aligned}
\frac{d \ln \left(w_{L N} / P\right)}{d t} \cdot\left|c_{j k}\right| & >\gamma\left[\int_{0}^{\bar{z}} \alpha(z) d z \cdot\left|c_{j k}\right|-\frac{\alpha(\bar{z})}{\int_{\bar{z}}^{1} \alpha(z) d z} c_{22} c_{33}+\frac{Y_{H N}}{w_{N}} c_{31} c_{22}\right] \\
& >\gamma\left[-\int_{0}^{\bar{z}} \alpha(z) d z \cdot c_{13} c_{31} c_{22}+\frac{Y_{H N}}{w_{N}} \cdot c_{31} c_{22}-\int_{0}^{\bar{z}} \alpha(z) d z \cdot c_{12} c_{21} c_{33}\right] .
\end{aligned}
$$

Note that $-\int_{0}^{\bar{z}} \alpha(z) d z \cdot c_{13}+Y_{H N} / w_{N}<0$. Therefore, when $\varepsilon_{N}(\cdot)$ is big enough, it is possible that $d \ln \left(w_{L N} / P\right) / d t>0$.

\section{A.7. Gini Data and Export Data}

The Gini data are from Deninger and Squire (1996) as updated in http://www.worldbank.org /research/growth/ dddeisqu.htm [deisqu2.exe or deisqu2.zip]. The countries selected for figure 1 are those satisfying 3 criteria. (a) The country had at least 2 years of consistent Gini data between 1978 and 1992 (except the Philippines which only has data between 1975 and 1985.) Where more than 2 years were available, preference was given to the start year closest to 1980 and the end year closest to 1990. (b) The start and end years of Gini data were separated by at least 3 years and preferably 10 years. (Only Cote d'Ivoire, Israel, and Turkey were separated by less than 5 years.) (c) Preference was given to Gini data that were based on household surveys of personal gross income in urban areas.

Export data are from Statistics Canada's World Trade Database as cleaned up and deflated by Antweiler and Trefler (2000). (Hereafter 'WTDB.') The period used for changes

in exports were chosen to match the period used for changes in Gini coefficients. There are three data imputations. (a) Taiwan is not in the WTDB. Instead we used IMF export data (denominated in U.S. dollars) deflated by the U.S. GDP deflator. Since this deflator is not quite comparable to that used in the WTDB, we then multiplied the Taiwan data by the ratio of WTDB to IMF growth rates for the East Asian countries in our sample. (b) Due to Chinese exports via Hong Kong, the export data for China and Hong Kong reported in the WTDB are misleading. Thus, we adjusted the Chinese and Hong Kong data using the information provided in table 2 of Feenstra et al. (1997) (c) Robert Lipsey has pointed out to us problems with the WTDB for Mexico. For Mexico we therefore used the OECD series 'exports of goods and services (volume index, 1990=100). 
Figure 1. Growth in Inequality and Trade During the 1980s

Non-East Asian Developing and Newly Industrialized Countries

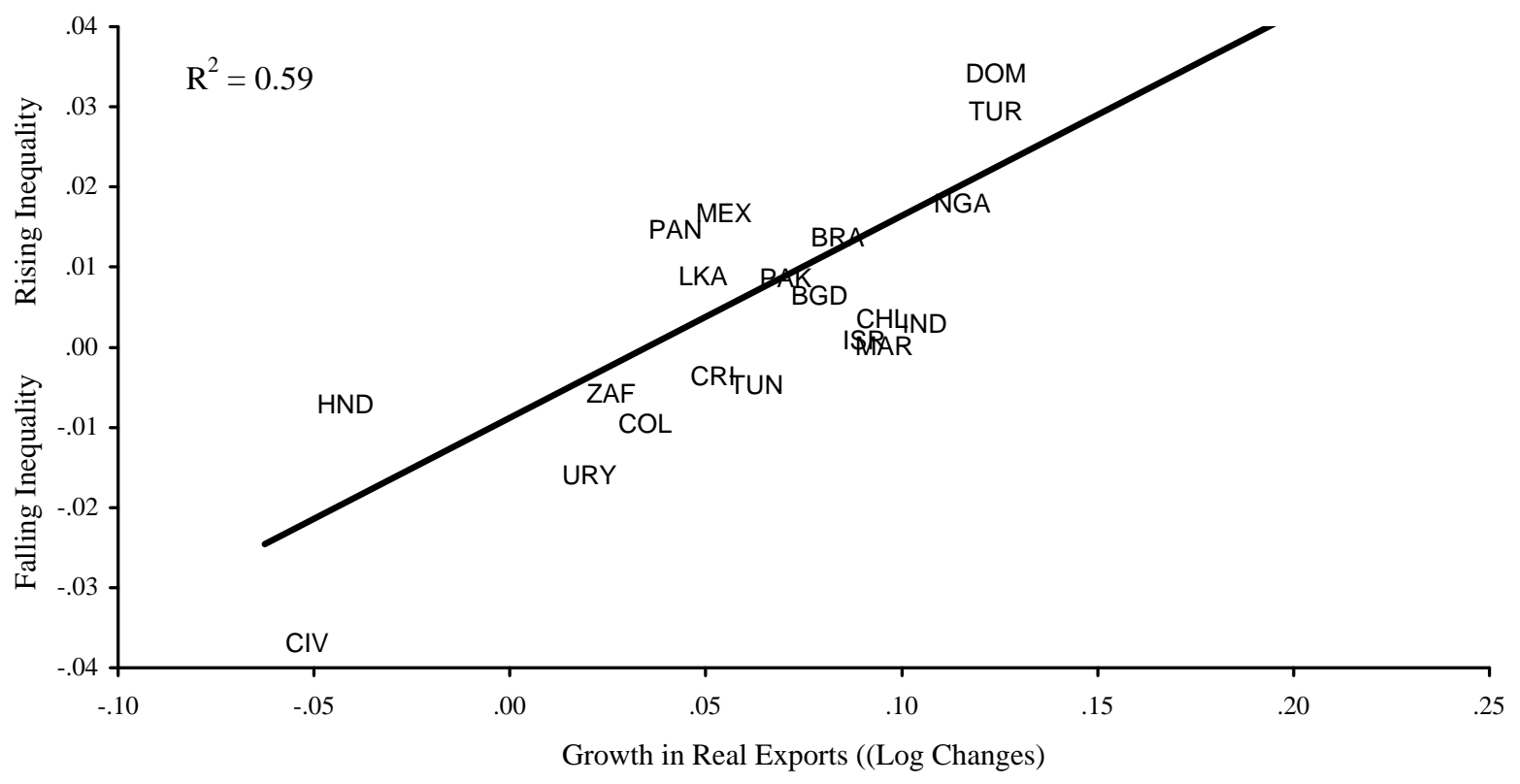

East Asia Developing and Newly Industrialized Countries

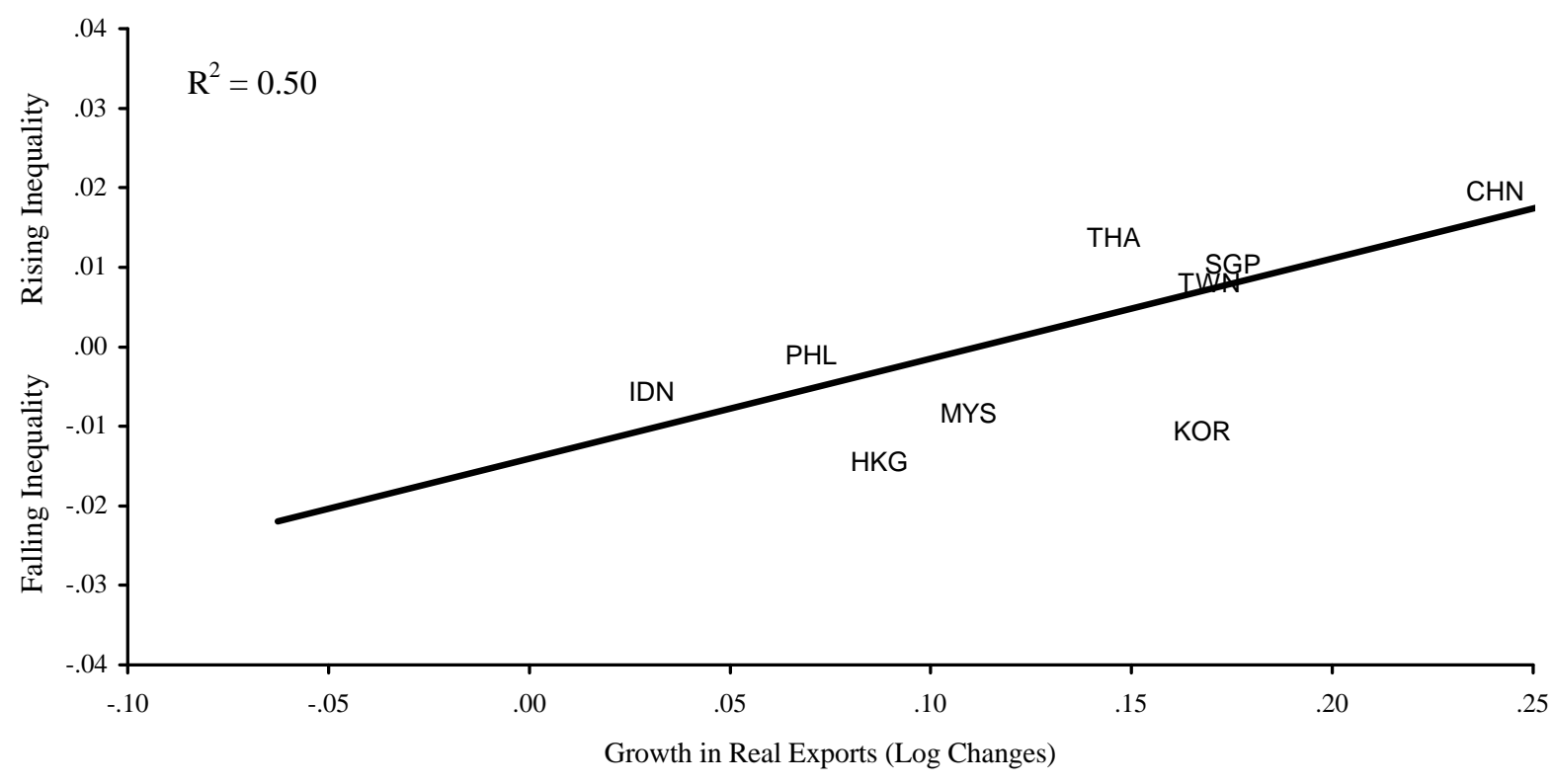

Notes: (a) The figures plot the change in Gini coefficients against the change in the log of real exports over the 1980s. (b) Data are from Deninger and Squire (1996). Where possible, we report Ginis calculated from surveys of urban wage earners. This corresponds to the the notion of inequality used in our model. See the appendix for futher data details. (c) The axes are identical for both panels so that the reader can visually overlay the two and obtain a similar positive relationship for all 29 countries. 


\section{Per Unit Production Cost}

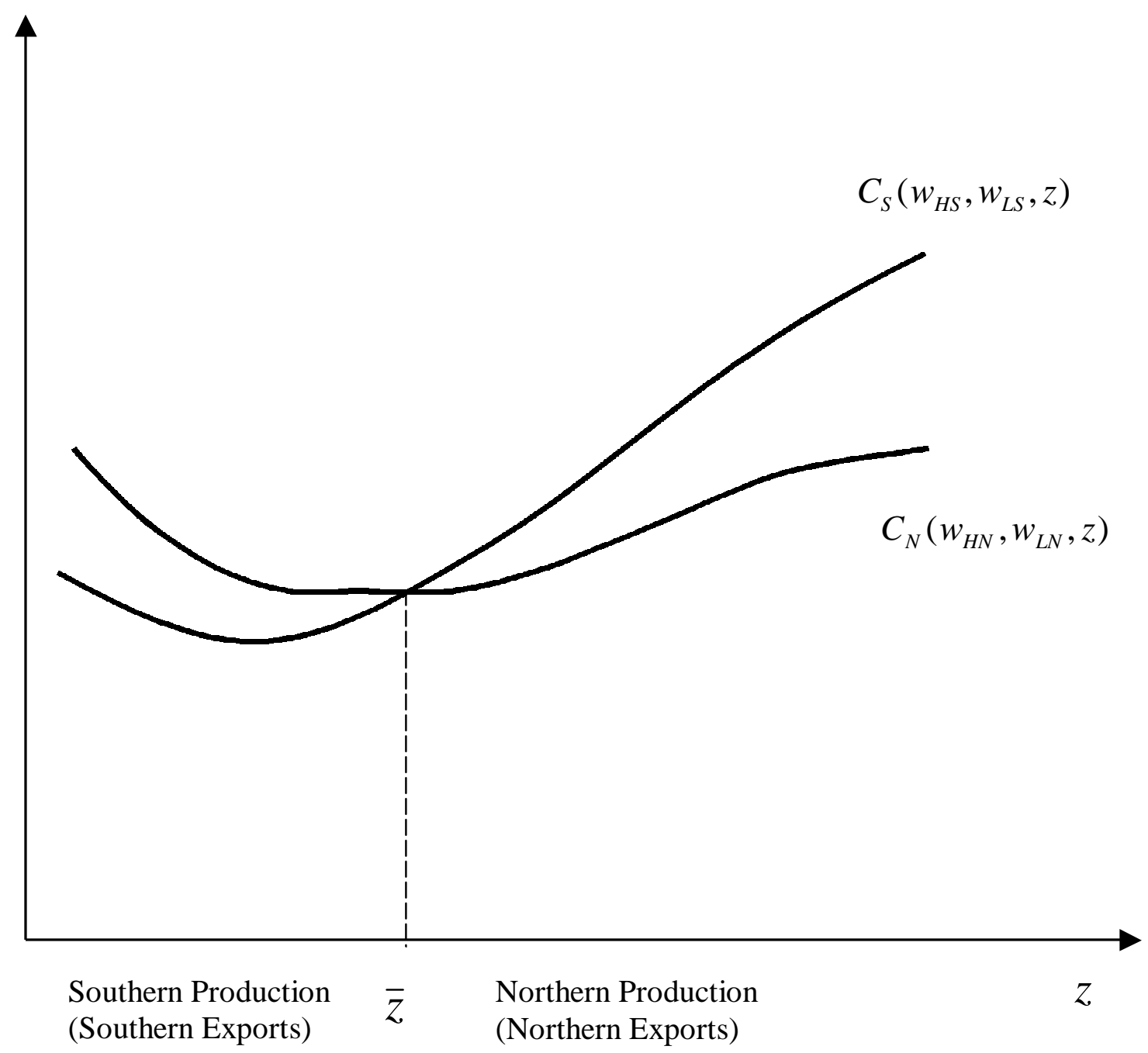

Figure 2. Equilibrium Trade Patterns 


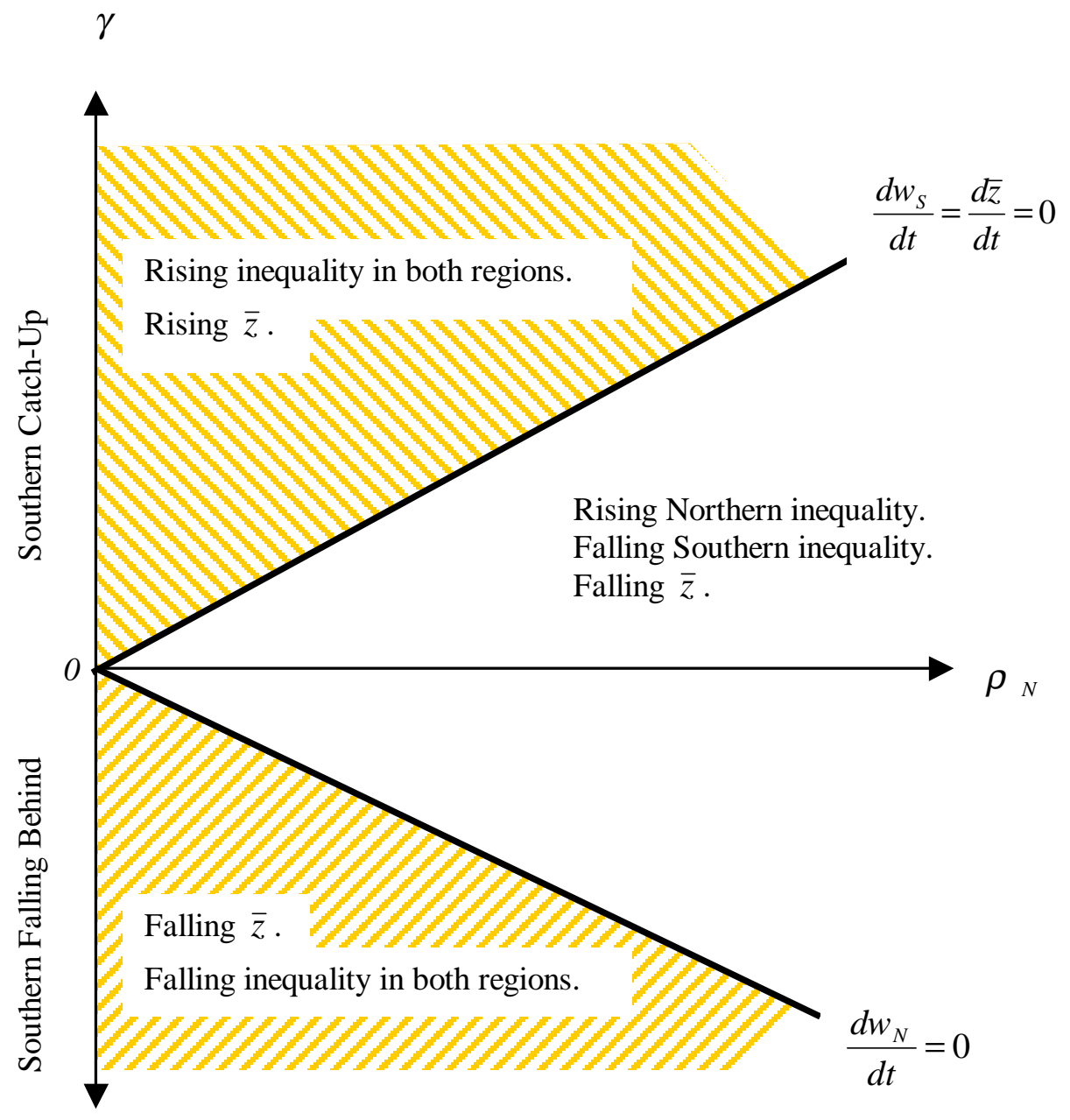

Figure 3.

Conditions for Rising Inequality and Changing Trade Patterns When $\rho_{S}=0$ 


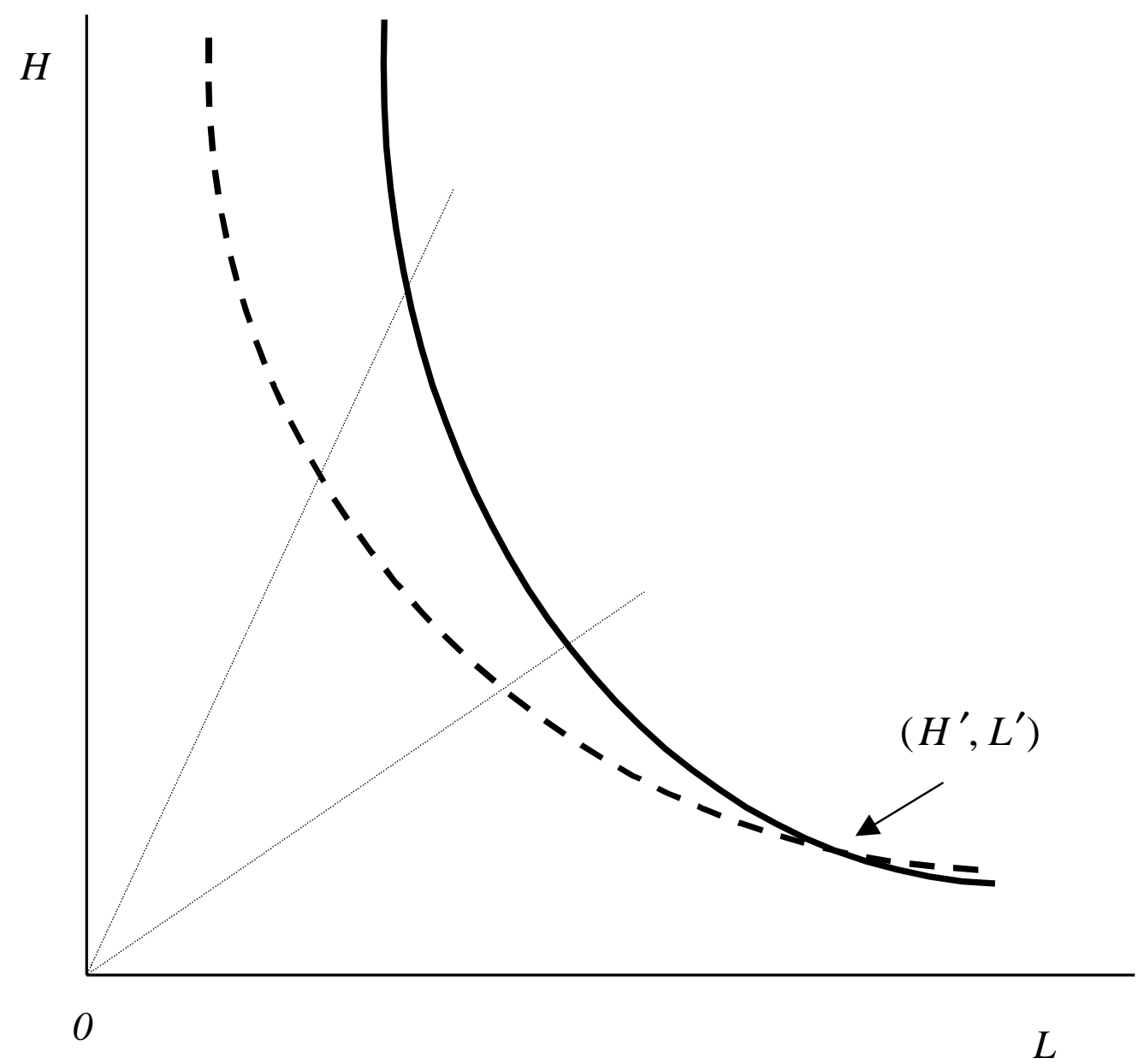

Figure 4.

Dependence of Southern Catch-Up on Initial Levels of $H$ and $L$ 
Table 1. Regression of Southern Skill Upgrading on Southern Catch-Up

\begin{tabular}{|c|c|c|c|c|c|c|}
\hline & & $\begin{array}{l}1978-82 \\
\text { and } \\
1984-90\end{array}$ & & $\begin{array}{c}1978-83 \\
\text { and } \\
1984-90\end{array}$ & $\begin{array}{c}1978-84 \\
\text { and } \\
1984-90\end{array}$ & $1978-90$ \\
\hline & (1) & (2) & (3) & (4) & $(5)$ & (6) \\
\hline Southern Catch-Up & 0.081 & 0.075 & 0.076 & 0.091 & 0.064 & 0.065 \\
\hline$C_{i j t}$ & $(3.75)$ & (3.61) & $(3.52)$ & $(4.22)$ & $(2.86)$ & $(2.08)$ \\
\hline Capital Deepening & 0.071 & 0.066 & 0.071 & 0.077 & 0.072 & 0.001 \\
\hline$\Delta \ln \left(K_{i j t} / V_{i j t}\right)$ & $(4.88)$ & $(4.67)$ & $(4.87)$ & $(5.78)$ & $(4.68)$ & $(0.03)$ \\
\hline National Skill Level & 0.309 & 0.308 & & 0.359 & 0.572 & \\
\hline$\Delta \ln \left(H_{i t} / L_{i t}\right)$ & $(2.98)$ & (2.99) & & $(3.47)$ & $(4.90)$ & \\
\hline 1984-90 Dummy & $\begin{array}{c}0.013 \\
(4.55)\end{array}$ & $\begin{array}{c}0.013 \\
(4.46)\end{array}$ & $\begin{array}{l}0.009 \\
(3.49)\end{array}$ & $\begin{array}{l}0.009 \\
(3.74)\end{array}$ & $\begin{array}{c}0.006 \\
(2.50)\end{array}$ & \\
\hline Country Dummies & yes & yes & yes & yes & yes & yes \\
\hline Industry Dummies & yes & no & yes & yes & yes & yes \\
\hline Observations & 959 & 959 & 959 & 959 & 964 & 487 \\
\hline$R^{2}$ & 0.16 & 0.14 & 0.15 & 0.19 & 0.18 & 0.33 \\
\hline
\end{tabular}

Notes: (a) The table reports estimates of equation (15). The dependent variable is skill upgrading i.e., the change in the payroll share of skilled workers over the indicated periods. Each observation corresponds to one of 28 industries in one of 18 Southern countries in one of 2 periods. $t$-statistics are in parentheses. $(b)$ In column 6 there is no time dimension so that the 1984-90 dummy and the national skill level must be omitted. (c) The sample means (standard errors) are as follows: Skill Upgrading 0.010 (0.041), Catch-Up 0.002 (0.076), Capital Deepening 0.036 (0.121), and National Skill Level 0.050 (0.017). 
Table 2. Choice of Trade Weights For Measuring Southern Catch-Up

\begin{tabular}{|c|c|c|c|}
\hline & $\begin{array}{l}\text { Import } \\
\text { Weights }\end{array}$ & $\begin{array}{c}\text { Export } \\
\text { Weights }\end{array}$ & $\begin{array}{c}\text { National } \\
\text { Trade } \\
\text { Weights }\end{array}$ \\
\hline Southern Catch-Up & 0.085 & 0.078 & 0.086 \\
\hline$C_{i j t}$ & $(3.93)$ & (3.69) & (3.99) \\
\hline Capital Deepening & 0.073 & 0.070 & 0.073 \\
\hline$\Delta \ln \left(K_{i j t} / V_{i j t}\right)$ & $(4.98)$ & $(4.83)$ & $(5.02)$ \\
\hline National Skill Level & 0.313 & 0.308 & 0.313 \\
\hline$\Delta \ln \left(H_{i t} / L_{i t}\right)$ & $(3.02)$ & $(2.97)$ & $(3.02)$ \\
\hline 1984-90 Dummy & $\begin{array}{l}0.013 \\
(4.58)\end{array}$ & $\begin{array}{l}0.013 \\
(4.59)\end{array}$ & $\begin{array}{l}0.014 \\
(4.66)\end{array}$ \\
\hline $\begin{array}{l}\text { Country Dummies } \\
\text { Industry Dummies }\end{array}$ & $\begin{array}{l}\text { yes } \\
\text { yes }\end{array}$ & $\begin{array}{l}\text { yes } \\
\text { yes }\end{array}$ & $\begin{array}{l}\text { yes } \\
\text { yes }\end{array}$ \\
\hline Observations & 959 & 959 & 959 \\
\hline$R^{2}$ & 0.16 & 0.16 & 0.16 \\
\hline
\end{tabular}

Notes: $(a)$ This table examines the sensitivity of the results to changes in the trade weights used to construct Southern catch-up. (b) The dependent variable is skill upgrading. See the main text for a complete description of the trade weights. See the notes to table 1 for a description of the regression specification. (c) $t$-statistics are in parentheses. 